\title{
RELAÇÕES ENTRE A RADIAÇÃO FOTOSSINTETICAMENTE ATIVA E A RADIAÇÃO GLOBAL EM PIRACICABA-SP
}

\author{
HILDEU FERREIRA DA ASSUNÇÃO \\ Engenheiro Agrônomo
}

Orientador: Prof. Dr. VALTER BARBIERI

Dissertação apresentada à Escola Superior de Agricultura "Luiz de Queiroz", da Universidade de são Paulo, para obtenção do título de Mestre em Agronomia, Área de Concentração: Agrometeorologia.

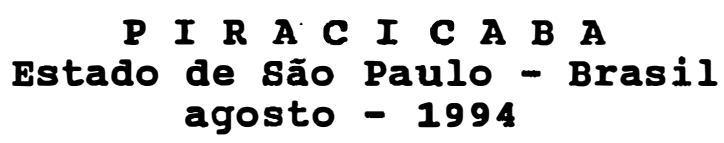


Ficha catalogŕáfica preparada pela Seção de Livros da Divisao de Biblioteca e Documentação - PCLQ/USP

Assunção, Hildeu Ferreira da

A851r Relações entre a radiação fotossinteticamente ativa e a radiação global em Piracicaba-SP. Piracicaba, 1993. $41 \mathrm{p}$.

Diss. (Mestre) - ESALQ

Bibliografia.

1. Meteorologia agrícola 2. Radiação fotossinteticamente ativa - Piracicaba 3. Radiação solar Piracicaba I. Escola Superior de Agricultura "Luiz de Queiroz", Piracicaba

CDD $\quad 630.276$

551.5271 


\title{
RELAÇÕES ENTRE A RADIAÇÃO FOTOSSINTETICAMENTE ATIVA E A RADIAÇÃO GLOBAL EM PIRACICABA-SP
}

\author{
HILDEU FERREIRA DA ASSUNÇÃO
}

\begin{abstract}
Aprovada em: 28/09/1994
Comissão julgadora:

Prof. Dr. Valter Barbieri (Orientador) ESALQ/USP

Prof. Dr. Luiz Roberto Angelocci ESALQ/USP

Prof. Dr. Ricardo Ferraz de oliveira ESALQ/USP
\end{abstract}

Prof. Dr. VALTER BARBIERI Orientador 
Em memória do meu pai, Manoel Canuto que sempre acreditou no meu trabalho e me ensinou a ser honesto acima de tudo. 
AGRADECIMENTOS

Desejo expressar minha gratidão às seguintes pessoas e Instituições que tornaram possível a execução deste Trabalho: - Ao Professor Valter Barbieri, pela orientação geral deste Trabalho;

- Aos Professores Antônio Roberto Pereira, Nilson Augusto Villa Nova, Luiz Roberto Angelocci e José Carlos Ometto, pelo incentivo, dedicação e contribuições prestadas;

- Aos demais Professores do Departamento de Física e Meteorologia: Klaus Reichardt, Paulo Leonel Libardi e Sérgio Moraes Oliveira, pelo ensino;

- Aos Professores Francisco Neto de Assis da UFPel, Eduardo Caruso Machado do IAC e José Roberto P. Parra da ESALQ, pelo empréstimo dos equipamentos; e ao Professor Ricardo Ferraz de oliveira pela participação da minha banca examinadora;

- Aos colegas de curso: Beatriz, Elcio, Eduardo, Enicildo, Marlene, Jean Paolo e Valéria pela grande amizade que adquirimos no decorrer do curso;

- Aos funcionários do Departamento de Física e Meteorologia da ESALQ: Ana Maria, Antônio José, Edvaldo, Fernando, Francisco, Márcia, Vanderlino e Robinson pela amizade e pela contribuição prestada direta e indiretamente a este Trabalho;

- Ao Professor e amigo Pedro Castro Neto da ESAL, pela minha primeira oportunidade na área de pesquisa;

- À Escola Superior de Agricultura "Luiz de Queiroz", da Universidade de São Paulo, pela oportunidade de frequientar o Curso de Pós-graduação;

- đ̀ CAPES, pelo apoio financeiro deste Trabalho.

O MEU MUITO OBRIGADO! 


\section{SUMÁRIO}

Página

LISTA DE FIGURAS

LISTA DE TABELAS • • • • • • • • • • • • • • • • • vii

LISTA DE ABREVIATURAS E SÍMBOLOS • • • • • • • • • . viii

RESUMO

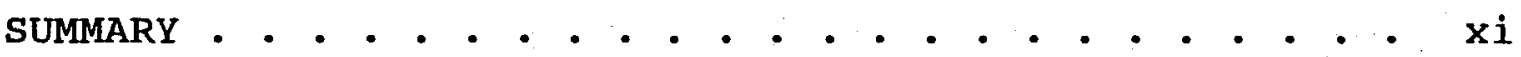

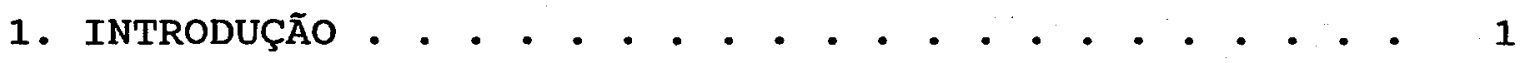

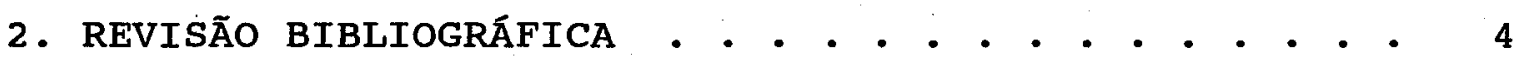

2.1. Histórico . . . . . . . . . . . . . . . 4

2.2. Fatores que afetam a intensidade da radiação solar . . . . . . . . . . . . . . . 5

2.3. Radiação Solar Extraterrestre . . . . . . . 5

2.3.1 Constante Solar . . . . . . . . . . . 6

2.3.2 Radiação no topo da atmosfera . . . . . 6

2.4. Atenuação da radiação solar pela atmosfera . . 7

2.4.1 Absorção da radiação solar . . . . . . 7

2.5. Radiação solar na superfície do solo . . . . . 8

2.5.1 Radiação global . . . . . . . . . . 9

2.6. Espectro eletromagnético . . . . . . . . . . 9

2.6.1 Radiação ultravioleta . . . . . . . . 9

2.6.2 Radiação Fotossinteticamente Ativa . . 10

2.6.3 Radiação Infravermelho próximo . . . . . 14

3. MATERIAL E MÉTOdos . . . . . . . . . . . . . . 15

3.1. Características Local e Instrumental . . . . 15

3.1 .1 Localização . . . . . . . . . . . . 15

3.1 .2 Instrumental . . . . . . . . . . 15

3.2. Metodologia . . . . . . . . . . . . 16

3.2 .1 Dados coletados . . . . . . . . . . 16 
3.2.2 Dados calculados . . . . . . . . . 17

3.2 .3 Correlações . . . . . . . . . . . . 18

4. Resultados E discussão . . . . . . . . . . . 20

4.1. Resultados obtidos com dados diários . . . 20

4.1.1 Relação da PAR/Qg . . . . . . . . . . 20

4.1.2 Relação PAR/Qg em função de n/N . . . . 25

4.1.3 Relação entre (Qg-NIR) em função de Qg • 27

4.1.4 Relações $Q g$, PAR e NIR em função de Qo e n/N . . . . . . . . . . . . . . . . 27

4.2. Resultados obtidos com dados horários . . . 30

4.2.1 Distribuição espectral horária média • . 30

4.2.2 Relações PAR/Qg em função da elevação solar 33

5. CONCLUSÕES .................... . . 40

REFERÊNCIAS BIBLIOGRÁFICAS . . . . . . . . . 4 42

APÊNDICE 1 . . . . . . . . . . . . . . . . . . . . 47

ÍNTEGRA DOS DADOS DIÁRIOS UTILIZADOS (1993) . . . 48

APENDICE 2 . . . . . . . . . . . . . . . . . . 53

INTEGRA DOS DADOS HORÁRIOS UTILIZADOS . . . . . . 54 
LISTA DE FIGURAS

Fig. $\quad \mathrm{n}$ ㅇ:

Página

Figura 1: (A) Espectro de Emissão de um Corpo Negro a $6000^{\circ} \mathrm{K}$; (B) Irradiância solar no Topo da Atmosfera $(\mathrm{m}=0)$; (C) Irradiância solar ao Nível do Mar $(m=1)$. ROBINSON (1966). . . . . 8

Figura 2: Distribuição espectral da radiação solar extraterrestre, da radiação ao nível do mar para um dia limpo e para um dia nublado e da radiação que penetra em uma cultura. (GATES, 1980) . . . . . . . . . . . . . . . . 10

Figura 3: Relação entre $\operatorname{PAR}\left(\mathrm{E} / \mathrm{m}^{2} \cdot \mathrm{dia}\right)$ e $\mathrm{gg}$ (MJ/m².dia) em Piracicaba-SP, em 211 dias, entre junho a dezembro de 1993. . . . . . . . 21

Figura 4: Relação entre $\operatorname{PAR}\left(\mathrm{MJ} / \mathrm{m}^{2} \cdot \mathrm{dia}\right)$ e $\mathrm{gg}$ (MJ/m².dia) em Piracicaba-SP para 30 dias com céu completamente nublado, observados no período de junho a dezembro de 1993 . . . . . 22

Figura 5: Relação entre PAR e Qg em Piracicaba-SP, para 146 dias com razão de insolação entre 0,1 e 0,9 no período de junho a dezembro de 1993.

Figura 6: Relação entre PAR e Qg em Piracicaba-SP para 35 dias completamente límpidos de junho a dezembro de 1993. . . . . . . . . . . . . 24

Figura 7: Relação PAR/Qg em função de (n/N) para Piracicaba-SP, durante 211 dias no período de junho a dezembro de 1993. . . . • . . . . 26

Figura 8: Relação da PAR obtida pelo método indireto (Qg-NIR) em função da radiação global para Piracicaba-SP, em 211 dias no período de junho a dezembro de 1993. . . . . . . . . 28

Figura 9: Radiação global em função da radiação no topo da atmosfera (QO) e da razão de insolação $(\mathrm{n} / \mathrm{N})$ para Piracicaba-SP, no 
período de junho a dezembro de 1993. • • • . . 29

Figura 10: Relação entre PAR e Qo em função da razão de insolação para Piracicaba-SP, durante 211 dias no período de junho a dezembro de 1993.

Figura 11: Relação entre NIR e Qo em função da razão de insolação para Piracicaba-SP, em 211 dias observados durante o período de junho a dezembro de 1993. . . . . . . . . . . . 32

Figura 12: Evolução horária da distribuição espectral da radiação solar e da fração fotossinteticamente ativa para dia com céu completamente limpo (média de 7 dias) . . . . . 34

Figura 13: Evolução horária da distribuição espectral da radiação solar e da fração fotossinteticamente ativa para dia com céu totalmente nublado (média de 7 dias) . . . . . 36

Figura 14: Relação entre PAR e $Q g$ em função da elevação solar para um dia completamente limpo, em Piracicaba-SP. . . . . . . . . . 38

Figura 15: Relação entre PAR e $\mathrm{Qg}$ em função da elevação solar para um dia completamente nublado, em Piracicaba-SP. . . . . . . . . 
LISTA DE TABELAS

Tab. ne:

Página

Tabela 1: Sensores Utilizados nas observações radiométricas. . . . . . . . . . . . . 15

Tabela 2: Razões de insolação médias, densidades de fluxos radiante médios de $\mathrm{Qg}$, PAR e NIR, fração $\eta=\mathrm{PAR} / \mathrm{Qg}$ e os desvios $(\sigma)$ médios mensais de $\eta$. . . . . . . . . . . . . . 25

Tabela 3: Distribuição espectral horária média das densidades de fluxos $Q 9$, PAR, NIR e UV, e respectivas porções $(\eta=\mathrm{PAR} / \mathrm{Qg}, \quad \iota=\mathrm{NIR} / \mathrm{Qg}$ e $\nu=U V / Q g)$ para um dia com céu completamente limpo. • • . . . . . . . . . . • . . 35

Tabela 4: Distribuição espectral horária média das densidades de fluxos Qg, PAR, NIR e UV, e respectivas porções para um dia com céu completamente nublado. . . . . . . . . . 35 
LISTA DE ABREVIATURAS E SÍMBOLOS

$\delta=$ declinação solar $\left({ }^{\circ}\right)$.

$\phi=$ latitude $\left({ }^{\circ}\right)$.

$\mathrm{H}=$ ângulo horário $\left({ }^{\circ}\right)$ ao nascer e pôr do sol.

$\mathrm{z}$ = ângulo zenital $\left({ }^{\circ}\right)$.

tn = tempo ao nascer do sol (horas).

tp = tempo ao pôr do sol (horas).

$B=$ ângulo da altura solar $\left({ }^{\circ}\right)$.

Para latitudes Norte $\circ$ sinal de $\delta$ e de $\phi$ é $(+)$ e para latitudes sul o sinal é $(-)$.

$\mathbf{N}=$ duração astronômica do dia (horas).

$\mathrm{n}=$ insolação (horas).

$\mathrm{n} / \mathrm{N}=$ razão de insolação.

$(\bar{D} / \mathrm{D})^{2}=$ Fator que expressa a variação da densidade de fluxo de radiação que atinge uma superfície normal aos raios solares, no Topo da Atmosfera, em virtude da distância variável da Terra em relação ao sol.

$\overrightarrow{\mathrm{D}}=$ Distância média Terra-Sol ( $\mathrm{m}$ ).

D = Distância instantânea Terra-Sol (m).

Qo = Radiação no Topo da Atmosfera.

Jo = Constante Solar $\left(1360 \mathrm{w} / \mathrm{m}^{2}\right)$.

PAR = Photosynthetically Active Radiation ou Radiação ou Radiação Fotossinteticamente Ativa.

NIR = Near Infrared Radiation ou Radiação Infraverelho Próximo.

Qg = Densidade de fluxo radiante Global.

UV = Densidade de fluxo radiante Ultravioleta.

$\eta=\mathrm{PAR} / \mathrm{Qg}$ ou fração fotossinteticamente ativa.

$\iota=\mathrm{NIR} / \mathrm{Qg}$ ou fração infravermelho próximo.

$\nu=U V / Q g$ ou fração ultravioleta. 


\title{
RELAÇÕES ENTRE A RADIAÇÃO FOTOSSINTETICAMENTE ATIVA E A RADIAÇÃo GLOBAL EM PIRACICABA-sP
}

\author{
Autor: HILDEU FERREIRA DA ASSUNÇÃO \\ orientador: Prof. Dr. VALTER BARBIERI
}

RESUMO

Mediu-se as densidades de fluxos radiantes de ondas curtas global (290 a $2800 \mathrm{~nm})$, fotossinteticamente ativa (400 a $700 \mathrm{~nm}$ ) e infravermelho próximo (700 a $2800 \mathrm{~nm}$ ), por 211 dias durante os meses de junho a dezembro de 1993 na Estação Agrometeorológica de Piracicaba, Estado de São Paulo, coordenadas geográficas de $22^{\circ} 42^{\prime} \mathrm{s}, 47^{\circ} 37^{\prime} \mathrm{W}$ e $570 \mathrm{~m}$ de altitude. Foram feitas várias análises de regressão linear em diferentes condições atmosféricas com o objetivo de estimar a fração PAR dentro da radiação global. As frações encontradas de $\eta=$ PAR/Qg foram $\eta=0,417$ para dias limpos, $\eta=0,429$ para dias parcialmente limpos e $\eta=0,496$ para dias nublados. No âmbito geral a estimativa da densidade de fluxo de fótons fotossintéticos em $\mathrm{E} / \mathrm{m}^{2}$.dia, independente das condições atmosféricas, foi $P A R=1,95 \mathrm{Qg}$, em que Qg é dado em $\mathrm{MJ} / \mathrm{m}^{2}$.dia, semelhante a $\eta=0,44 \pm 0,04$. A análise de regressão linear indicou a contribuição da porção fotossinteticamente ativa dentro da radiação global em função da razão de insolação $(n / N)$ como PAR/Qg=0,501-0,102n/N. A estimativa da radiação fotossinteticamente ativa determinada pelo método indireto, $\quad \mathrm{PAR}=(\mathrm{Qg}-\mathrm{NIR})$, gerou $[\mathrm{Qg}-\mathrm{NIR}]=0,533 \mathrm{Qg}$. As estimativas das densidades de fluxo, em função da radiação no topo da atmosfera (QO) e da razão de insolação ( $\mathrm{n} / \mathrm{N}$ ), foi $\operatorname{PAR}=Q \circ[0,498+0,816(\mathrm{n} / \mathrm{N})]$ para fótons fotossintéticos em 
$\mathrm{E} / \mathrm{m}^{2} . \mathrm{dia}, Q g=Q \circ[0,224+0,466(\mathrm{n} / \mathrm{N})]$ para $\mathrm{global} \mathrm{em} \mathrm{MJ} / \mathrm{m}^{2} . \mathrm{dia} e$ $\operatorname{NIR}=Q \circ[0,091+0,239(\mathrm{n} / \mathrm{N})]$ para infravermelho próximo em $\mathrm{MJ} / \mathrm{m}^{2}$.dia. Também determinou-se a variação horária de PAR/Qg em função do horário solar em condições de céu limpo e em condições de céu nublado, obtendo-se como média horária $\eta=0,45$ para dias claros e $\eta=0,56$ para dias nublados. Fazendose análises de regressão linear em PAR/Qg, ambos em unidades de $w / m^{2}$, em função da elevação solar (B) sob céu claro e sob céu nublado obteve-se a expressão $\operatorname{PAR}=Q g[0,5117-0,00185(B)]$ para dias de céu limpo, e $P A R=Q 9[0,5908-0,00076(\beta)]$ para dias de céu nublado. Com a subtração Qg-(PAR+NIR) estimou-se a radiação ultravioleta que variou nas condições atmosféricas de Piracicaba, em termos médios, de 8 a $12 \%$ dentro do fluxo radiante global. 
RELATIONSHIPS BETWEEN PHOTOSYNTHETICALLY ACTIVE
RADIATION AND SOLAR RADIATION IN PIRACICABA-SP, BRAZIL

Author: HILDEU FERREIRA DA ASSUNÇÃo Adviser: Prof. Dr. VALTER BARBIERI

Measurements of total solar (290 to $2800 \mathrm{~nm})$, photosynthetically active (400 to $700 \mathrm{~nm}$ ) and near-infrared (700 to $2800 \mathrm{~nm}$ ) irradiance were made for 211 days, during the period of june to december of 1993, in the agrometeorological station at Piracicaba-SP, Brazil, $22^{\circ} 42^{\prime} \mathrm{S}$, $47^{\circ} 37^{\prime} \mathrm{W}$, and $570 \mathrm{~m}$ of altitude. The objective of this experiment was to obtain equations to estimate the photosynthetic photon flux density (PAR) and near-infrared (NIR) incoming solar radiation (Qg), in differents atmospheric condictions. The $\eta=\mathrm{PAR} / \mathrm{Qg}$ was $\eta=0.417$ in clear days, $\eta=0.429$ in partially cloudy days and $\eta=0.496$ in cloudy days condictions, for global solar irradiance. The daily photosynthetically active radiation, in units of $\mathrm{E} / \mathrm{m}^{2}$.day, was PAR=1.95Qg, corresponding to $\eta=0.44 \pm 0.04$ times the solar irradiance $(\mathrm{Qg})$ value, in units of $\mathrm{MJ} / \mathrm{m}^{2}$.day, independent of the atmospheric condictions. The analysis of linear regression to photosynthetically active portion, in function of the solar radiation and of sunshine ratio $(n / N)$, pointed PAR=Qg $(0.501-0.102 \mathrm{n} / \mathrm{N})$. The photosynthetically active radiation obtained to indirect method, $P A R=(Q g-N I R)$, resulted in PAR=0.5339g. Similar results of PAR was estimated, in units of $\mathrm{E} / \mathrm{m}^{2}$.day, in relation to extra-terrestrial (QO) radiation, in units of $\mathrm{MJ} / \mathrm{m}^{2}$.day, sunshine ratio ( $\left.\mathrm{n} / \mathrm{N}\right)$ was 
found $P A R=00[0.498+0.816(n / N)]$. The estimation for nearinfrared $\left(\mathrm{MJ} / \mathrm{m}^{2}\right.$.day) as function of the extra-terrestrial radiation and shunshine ratio was obtained $\operatorname{NIR}=00[0.091+0.239(\mathrm{n} / \mathrm{N})]$. The hourly variation of $\eta$ to atmospheric condictions was 0.45 for clear day, and 0.56 for cloudy day of the solar instantaneous flux density. The linear equation to estimate PAR as a function of solar instantaneous flux density $(\mathrm{Qg})$, in units of $\mathrm{W} / \mathrm{m}^{2}$, and solar elevation (B) for cloudy day was $P A R=Q g[0.5908-0.00076(B)]$, and $P A R=Q g[0.5117-0.00185(B)]$ for clear day. In the improvement of residue Qg-(PAR-NIR), obtained the ultraviolet (UV) radiation that varied, in average terms, of 8 to $12 \%$ into global flux density in the atmospherics condictions from Piracicaba, state of São Paulo. 


\section{INTRODUÇÃo}

Apesar do vasto conhecimento do homem acerca dos processos físicos, químicos e biológicos na natureza, há muito ainda o que se pesquisar sobre eles. Um fator físico de grande destaque, intrinsicamente ligado a todos os processos naturais, é a energia da qual o sol é a principal fonte fornecedora para a superfície da Terra.

Em toda história das civilizações o homem obteve da natureza a energia para suprir suas necessidades, utilizando-se fontes renováveis. Além dos ventos, dos rios e mesmo das marés, ele sempre usufruiu da energia solar armazenada nas plantas, através da fotossíntese, o que the permitiu não somente suprir-se das calorias de que necessitava seu organismo como, também, da madeira para outros usos energéticos, principalmente nos últimos 100 anos para fins industriais e transporte.

Com a chamada "crise do petróleo", alterou-se profundamente a tendência do uso exclusivo deste combustível, levando os povos a repensar seus planejamentos energéticos e voltarem à trilha histórica oferecida pela natureza, pois em menos de um século teremos gasto a reserva de petróleo que a natureza levou milhões de anos para formar.

Esta conscientização vem acarretando uma volta as fontes renováveis de energia, com a busca cada vez maior do uso da energia solar, direta ou indireta. o sol é um imenso reator a fusão nuclear, sendo sua radiação responsável, na Terra, pela formação dos ventos, pelo crescimento das plantas, pela atividade biológica dos 
animais, inclusive do homem pelas variações climáticas e, em outras épocas, em determinadas condições pela própria formação do carvão e do petróleo.

A maneira mais simples e racional do homem usufruir da energia solar é, obviamente armazená-la através da fotossíntese, em plantas como a cana-de-açúcar, mandioca, milho, soja, babaçu e outras, e transformá-la em álcool etílico e óleo. Combustíveis líquidos renováveis, de indiscutíveis viabilidade técnica e econômica, para países como o Brasil, que dispõem de grandes áreas ainda não utilizadas, a maioria das quais situadas na parte tropical do globo onde chega a maior densidade de fluxo radiante do planeta.

A quantidade de energia radiante recebida pela Terra proveniente do sol em um único dia é cerca de 3,67 x $10^{21} \mathrm{cal}$, comparável somente à energia gerada por aproximadamente 18 milhões de usinas com a grandeza de ITAIPU, que se fosse totalmente coletada e armazenada seria suficiente para manter todas as indústrias e domicilios do mundo durante 100 anos. Todavia, isto não seria possível, uma vez que, grande parte dela é usada no aquecimento do ar e do solo, no processo fotossintético dos vegetais, na evaporação da água e na circulação geral da atmosfera, afim de que o ciclo hidrológico seja mantido.

Considerando-se o processo biológico, o espectro radiante do sol é praticamente dividido em três faixas distintas de comprimentos de ondas, as quais são ultravioleta, de 290 a $400 \mathrm{~nm}$, visível, de 400 a $700 \mathrm{~nm}$ e infravermelho próximo, de 700 a $2800 \mathrm{~nm}$ (MONTEITH \& UNSWORTH, 1990). A banda visível, também denominada de Radiação Fotossinteticamente Ativa ou PAR é de grande importância para os vegetais, uma vez que, estes são capazes de absorverem a luz solar e converterem-na em energia química, na forma de carboidratos. Este processo é conhecido por fotossíntese.

A Radiação Fotossinteticamente Ativa não é 
rotineiramente medida nas estações meteorológicas, no entanto é constantemente requerida com vários propósitos agronômicos, tais como, na modelagem da fotossintese e na modelagem da produção de culturas de interesse econômico. Na modelagem da fotossintese considera-se a fração PAR para dias completamente limpos ou para dias encobertos. Portanto, para dias parcialmente limpos ou encobertos a fração PAR não é facilmente estabelecida, visto a grande quantidade de fatores que a influenciam.

o presente trabalho, portanto, tem como objetivo estabelecer relações da densidade de fluxo de fótons fotossintéticos (PAR) e da densidade de fluxo de radiação infravermelho próximo (NIR) tanto com a radiação global (Qg) como a radiação no topo da atmosfera (Q०), em função da época do ano, da razão de insolação $(\mathrm{n} / \mathrm{N})$ e do ângulo de elevação solar ( $(B)$ nas condições atmosféricas de Piracicaba-sP. 


\section{REVISÃo BIBLIOGRÁFICA}

\subsection{Histórico}

As primeiras investigações sobre o sol surgiu praticamente com Galileu Galilei (1564-1642), após a invenção do telescópio. Galileu, seus contemporâneos e seus sucessores fizeram incansáveis observaçōes visuais da luz do sol, estudando em detalhes o comportamento das manchas solares e as características de rotação do sol. o físico, matemático e astrônomo alemão, Christian Huygens (1629-1695) criou a Teoria Elementar da Onda. Em 1666 Isaac Newton descobriu o caráter espectral da luz solar, e decompôs a faixa visível em componentes monocromáticos, com o auxílio de prismas óticos. Daí então criou-se a Teoria Corpuscular da Luz Natural, explicando a refração, a reflexão e a propagação da luz em diferentes meios. Desde Galileu, muitos estudiosos contribuíram para a elaboração de uma teoria mais convincente sobre a luz, baseada em conceitos físicos até a invenção de instrumentos capazes de registrar com precisão a intensidade radiante do sol.

A instrumentação radiométrica cresceu significativamente no final do século XIX com Knut Ångström (1857-1910), inventor do Pireliômetro de compensação elétrica que serviu como padrão absoluto para determinar a energia radiante em muitos países do mundo. o princípio básico foi empregado mais tarde por Anders Knut Ångström, na construção de um novo tipo de instrumento (pirgeômetro) destinado a registrar medidas noturnas da radiação atmosférica de ondas longas. Após a Segunda Grande Guerra o trabalho instrumental 
avançou muito mais, mediante à associação com o programa Espacial Americano e o desenvolvimento de satélites Meteorológicos, produzindo-se instrumentos mais eficientes e novas técnicas de medidas mais rígidas.

\subsection{Fatores que afetam a intensidade da radiação solar}

A radiação emitida pelo sol sofre variações na sua intensidade antes de atingir a superficie terrestre em função de vários fatores. Estas variações são atribuídas a fatores astronômicós devido às alternâncias anuais da distância Terra-Sol, da declinação solar e do ângulo horário. A distribuição da densidade de fluxo radiante em um determinado local é geograficamente dependente da latitude, da longitude e da altitude; e geometricamente dependente dos ângulos zenital, azimutal, da inclinação da superfície e do azimute do plano inclinado. Ao penetrar na atmosfera a energia radiante está sujeita a atenuações causada por fatores físicos como: a quantidade de vapor d'água na atmosfera, o coeficiente de extinção atmosféricico; o coeficiente de turbidez ou poluentes, o expoente de turbidez de Ångström, o conteúdo de ozônio, o tipo de nuvem e a razão de insolação (ROBINSON, 1966).

Todos estes fatores contribuem de maneira direta no ciclo de variação diário e anual da intensidade radiante. Tomando-se conhecimentos destas variáveis é possivel fazer estimativas precisas do fluxo radiante que atinge o solo a cada unidade de tempo (COULSON, 1975).

\subsection{Radiação solar Extraterrestre}

o sol é uma esfera gasosa, cuja temperatura na sua superficie é cerca de $6000^{\circ} \mathrm{K}$. No seu interior ocorre a fusão nuclear do hidrogênio, produzindo enorme quantidade de energia a qual é emitida por esta estrela (COULSON, 1975). somente cerca de um bilionésimo da energia emitida pelo sol atinge a Terra, mas esta pequena fração é o bastante para 
manter ativo todos os processos físicos, químicos e biológicos do planeta (SELLERS, 1967).

\subsubsection{Constante solar (Jo)}

o conceito de Constante solar foi introduzida por A. Pouillet em 1837, afim de facilitar seus cálculos. o primeiro método de determinação foi proposto por Langley em 1881 (ROBINSON, 1966). A Constante solar é definida como um fluxo de energia radiante sobre uma superficie fora da atmosfera em uma unidade de área e de tempo, orientada normalmente ao feixe de raios solares numa distância média Terra-Sol (ROBINSON, 1966; COULSON, 1975).

A primeira medida direta da constante solar feita acima da camada de ozônio, em 1967 por um foguete X-15 em Nevada (LAUE \& DRUMMOND, 1968), foi $1,951 \mathrm{cal} / \mathrm{cm}^{2} \cdot \mathrm{min}$. A padronização da Constante solar adotada pela NASA, após a avaliação de diferentes resultados obtidos em topos de montanhas, balões, foguetes, aeronaves e satélites, é de 1,94 $\pm 0,03 \mathrm{cal} / \mathrm{cm}^{2} . \mathrm{min}$ ou $1353 \mathrm{~W} / \mathrm{m}^{2}$, este valor é quase $3 \%$ menor que o obtido por JONHSON ${ }^{1}$ (1954) citado por COULSON (1975) e LAUE \& DRUMMOND (1968).

\subsubsection{Radiação no topo da atmosfera (QO)}

Em virtude da forma elíptica da órbita terrestre, a distância Terra-sol varia ao longo do ano em torno de um valor médio de $149,6 \times 10^{6} \mathrm{~km}$, denominado de Unidade Astronômica (UA) - A distância mínima Terra-Sol, designada de Periélio é de aproximadamente 147,1 x 106 km, enquanto que a distância máxima, Afélio, é de 152,1 x 106 km. (VIANELLO \& ALVES, 1991). Apesar da excentricidade da órbita ser pequena, esta afeta em quase 7\% a diferença no fluxo de energia solar no topo da atmosfera entre o Periélio e o

${ }^{1}$ JONHSON, F. S.,1954. The Solar Constant. J. Meteorol . 11:431439 . 
Afélio (COULSON, 1975). Portanto a radiação no topo da atmosfera varia basicamente em função da latitude e da época do ano.

\subsection{Atenuação da radiação solar pela atmosfera}

Além de fenômenos que ocorrem na própria fonte de energia (Sol) tais como manchas e erupções solares, e dos efeitos astronômicos na variação da intensidade da radiação solar, a quantidade de radiação que chega à superfície da Terra dependerá também de outros fatores associados à atmosfera terrestre. Trata-se, portanto de um assunto complexo (vide GOODY, 1964; ROBINSON, 1966; SELLERS, 1967; COULSON, 1975; GATES, 1980 e MONTEITH \& UNSWORTH, 1990 para detalhes). Ao passar pela atmosfera terrestre, a radiação solar é atenuada por espalhamento e absorção (MONTEITH \& UNSWORTH, 1990; VIANELLO \& ALVES, 1991).

\subsubsection{Absorção da radiação solar}

No espalhamento não há perda de energia, já na absorção pode haver alterações da temperatura, da composição química e outras propriedades da partícula do ar (ROBINSON, 1966). A absorção em geral é seletiva, o ozônio é responsável pela absorção do espectro do ultravioleta, o vapor d'água e - gás carbônico absorvem intensamente a banda do infravermelho, assim como outros gases tais como $\circ \mathrm{O}_{2}, \mathrm{~N}_{2} \mathrm{O}, \mathrm{CH}_{4}$ além de poeiras, fuligens, gotículas de nuvens, etc. (veja Figura 1, página 8). As áreas sombreadas mostram as bandas de absorção dos diferentes gases atmosféricos. Na região visível do espectro, a absorção por gases é de pouca importância, no infravermelho porém, a absorção é muito mais importante que - espalhamento. o vapor d'água na atmosfera aumenta notavelmente a proporção de radiação visível em relação ao infravermelho (MONTEITH \& UNSWORTH, 1990) que chega à superfície terrestre. 


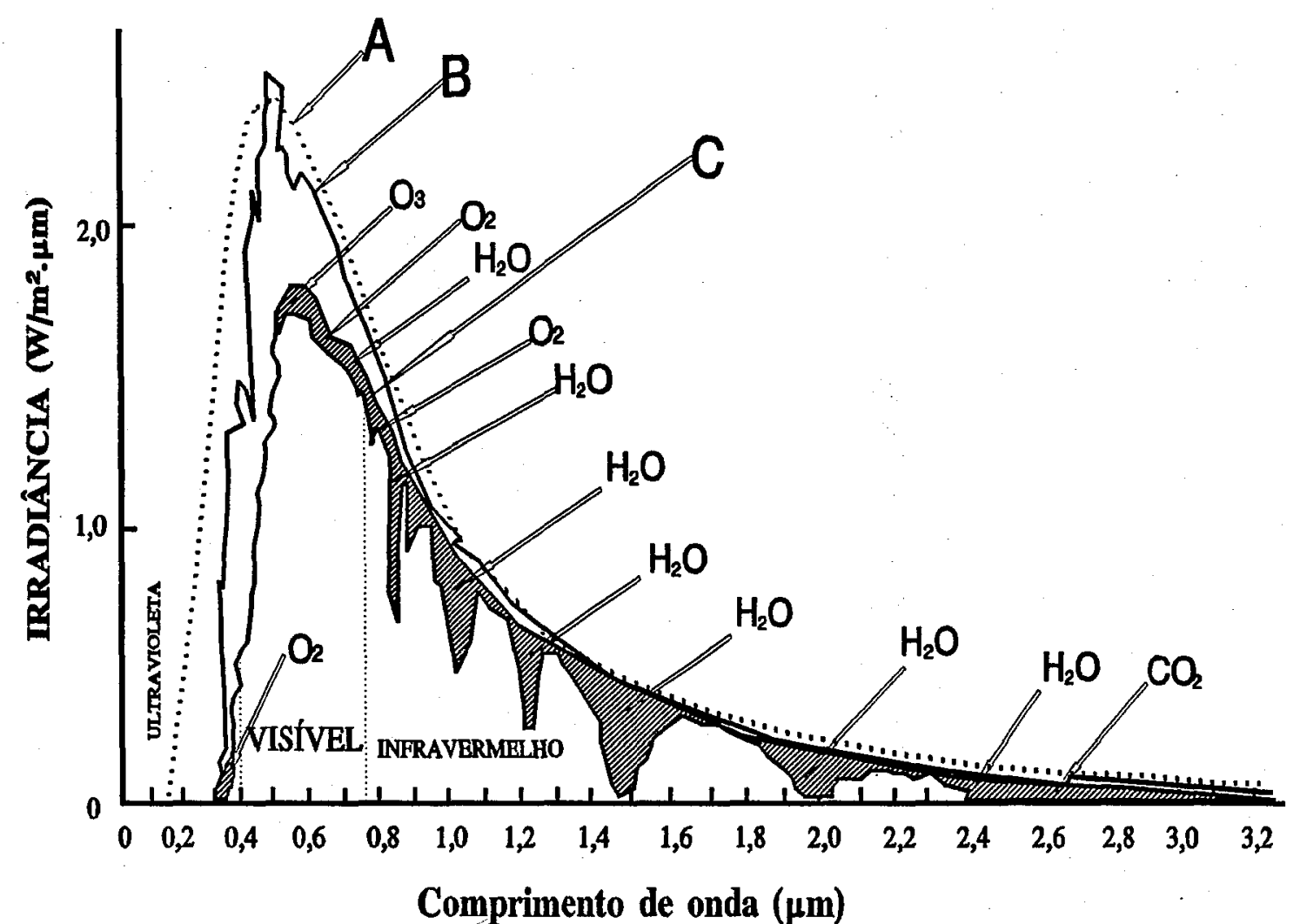

Figura 1: (A) Espectro de Emissão de um Corpo Negro a $6000^{\circ} \mathrm{K}$; (B) Irradiância Solar no Topo da Atmosfera $(m=0)$; (C) Irradiância Solar ao Nível do Mar ( $m=1)$. ROBINSON (1966).

\subsection{Radiação solar na superfície do solo}

A irradiância solar incidente num plano horizontal é transmitida na atmosfera de acordo com a lei de Bouguer-Lambert. A transmitância atmosférica para a radiação solar é uma fração da radiação incidente no topo da atmosfera que chega ao solo na vertical do local (ROBINSON, 1966).

Levando-se em consideração os efeitos do espalhamento e da absorção pelos constituintes atmosféricos, a maior porção da radiação solar que chega à superfície do solo, sob condições de céu limpo e sem interagir com a atmosfera é denominada de radiação direta, podendo ser quantificada por um Pireliômetro. A outra parcela de energia radiante, provocada pelo espalhamento atmosférico, é chamada de radiação difusa, a qual chega à superfície do solo, variando com o ângulo zenital do Sol (COULSON, 1975). Em dias 
de céu limpo, a radiação difusa contribui com aproximadamente $15 \%$ do total que chega à superfície (VIANELLO \& ALVES, 1991).

\subsubsection{Radiação global (Qg)}

A quantidade total de energia radiante recebida pela superfície de um determinado local em um dia é a soma da energia direta mais a energia difusa. A melhor forma de quantificar a irradiância global diária é através do Piranômetro (COULSON, 1975). Entretanto, em virtude da escassez de dados meteorológicos de tal natureza, torna-se necessário recorrer a fórmulas empíricas que permitem estimar a irradiância solar em função de outros parâmetros meteorológicos como: nebulosidade, duração do brilho solar, etc. (ROBINSON, 1966; OMETTO, 1968; VIANELLO \& ALVES, 1991).

\subsection{Espectro eletromagnético}

E o conjunto de radiaçōes eletromagnéticas ordenadas de acordo com as suas frequiências, seus comprimentos e números de ondas conforme a Figura 2 na página 10, na qual cada curva representa a energia incidente numa superfície horizontal. Vê-se ainda a distribuição espectral da radiação solar direta, mostrando a segmentação do espectro considerando-se os processos biológicos de vegetais. 1=azul, $2=$ verde-amarelo e 3=vermelho.

\subsubsection{Radiação ultravioleta (UV)}

- espectro ultravioleta, faixa compreendida entre 200 a $400 \mathrm{~nm}$, pode ser dividido em A.(400 a $300 \mathrm{~nm}$ ), B $(300$ a $290 \mathrm{~nm})$ e C (290 a $200 \mathrm{~nm})$. A faixa de 290 a $400 \mathrm{~nm}$ é parcialmente transmitida pela atmosfera, e pode causar efeitos biológicos de grande importância. Felizmente todo comprimento de onda abaixo de $290 \mathrm{~nm}$, potencialmente nocivo, é absorvido por gases atmosféricos, principalmente pelo ozônio (ROBINSON, 1966; COULSON, 1975). É evidente que pouca radiação ultravioleta chega à superfície do solo, bem como 


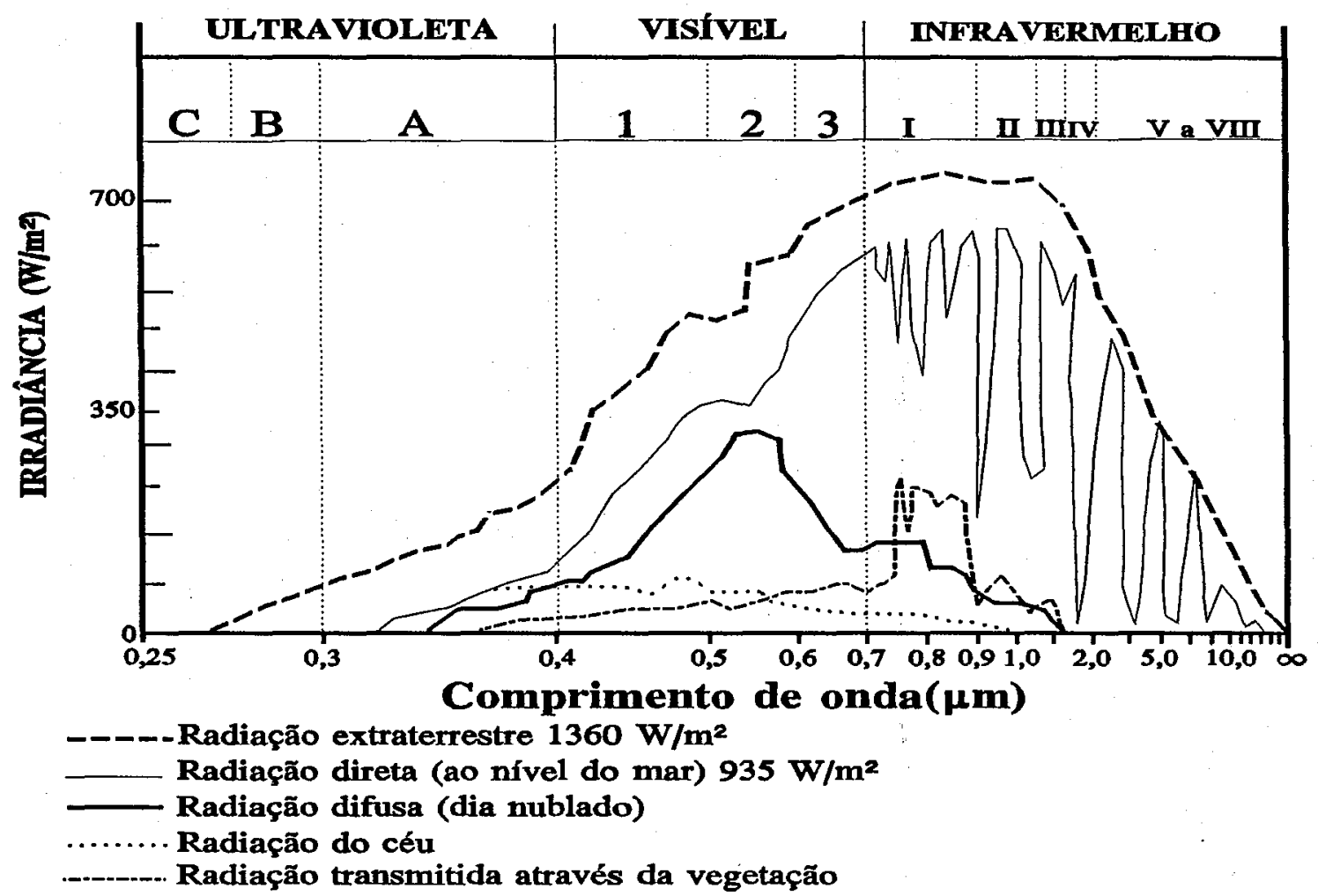

Figura 2: Distribuição espectral da radiação solar extraterrestre, da radiação ao nível do mar para um dia limpo e para um dia nublado e da radiação que penetra em uma cultura. (GATES, 1980).

maiores intensidades deste fluxo são observadas em lugares altos como topos de montanhas, podendo chegar ao nível de até 9: da radiação global (GATES, 1980).

\subsubsection{Radiação Fotossinteticamente Ativa (PAR)}

E a faixa para a qual o olho humano é sensivel, cujo comprimento de onda inicia-se no azul (400 nm), prolongando-se até o vermelho extremo $(700 \mathrm{~nm})$. A fotossíntese é estimulada pela radiação no mesmo comprimento de onda a qual é denominada de Radiação Fotossinteticamente Ativa ou PAR (MONTEITH \& UNSWORTH, 1990). Inicialmente, a PAR era medida em unidade de densidade de fluxo de energia $\left(\mathrm{W} / \mathrm{m}^{2}\right)$, mas gradualmente foi sendo substituída pela densidade de fluxo de fótons fotossintéticos $\left(\mu \mathrm{E} / \mathrm{m}^{2} . \mathrm{s}\right)$. 
A radiação fotossinteticamente ativa pode ser determinada basicamente por dois métodos: direto e indireto. No método indireto considera-se o fluxo fotossinteticamente ativo, a faixa espectral nos comprimentos de ondas entre 220 a $686 \mathrm{~nm}$ (LAUE \& DRUMMOND, 1968), não diferindo significativamente das frações entre os comprimentos de ondas de 370 a $730, \mathrm{~nm}$ examinado por MCCREE (1971-72) ou de 380 a $710 \mathrm{~nm}$ definido por YEFIMOVA ${ }^{2}$ (1971) citado por STANHILL \& FUCHS (1976). Este método consiste na utilização de dois Piranômetros, um equipado com filtro WG-295, destinado a quantificar a densidade de fluxo radiante global, e o outro equipado com filtro RG-695 para medir a densidade de fluxo da radiação infravermelho próximo. o espectro visível é convenientemente estimado subtraindo-se da densidade de fluxo radiante total, a densidade de fluxo da banda do infravermelho (SZEICS, 1974; STIGTER \& MUSABILHA, 1982; PEREIRA et al, 1982; HANSEN, 1984; MACHADO et al, 1985 e KARALIS, 1989).

No método direto adota-se a faixa espectral de 400 a $700 \mathrm{~nm}$ (MCCREE, 1972), cuja medida é feita diretamente por um sensor quântico que opera nesta faixa do espectro ou pode ser medido também por um espectro-radiômetro, quantificando a densidade de fluxo de fótons fotossintéticos. Este processo foi adotado por vários pesquisadores: BRITTON \& DODD (1976); HOWELL \& MEEK (1983); HIPPS (1983); MEEK \& HATFIELD (1984); MCCREE (1984); WEISS \& NORMAN (1985); BLUM \& SCHWANK (1985); GUEYMARD (1989) e ASSIS \& MENDES (1989).

A desvantagem principal do método indireto na determinação da PAR é que a porção visível fica acrescida da faixa ultravioleta, embora na verdade haja uma pequena contribuição do ultravioleta na fotossíntese (MCCREE, 1971-

\footnotetext{
${ }^{2}$ YEFIMOVA, N. A., 1971. Geographical distribution of the sums of photosynthetically active radiation. Soviet Geography: Review and Translation. 12:66-74
} 
72 ; COULSON, 1975), pouco significativa. Desta maneira há o inconveniente de que tal superestimativa seja utilizada em modelagens, uma vez que a fração ultravioleta pode superar os 9: da radiação global citado por GATES (1980).

As primeiras medidas da densidade de fluxo de fótons fotossintéticos tiveram como objetivos as determinações da fração visível dentro do espectro global e a fração espectral absorvida na produção da fotossíntese em plantas (MCCREE, 1971-72). Este autor propôs ainda uma definição padrão para a radiação fotossinteticamente ativa, estabelecendo a densidade de fluxo relativo $(\eta)$ em diferentes fontes de luz, natural e artificial (MCCREE, 1972). Tais estimativas consideram todo um processo com influências de caráter astronômico, geográfico, geométrico, físico e meteorológico no espectro global de radiação.

Maiores influências na variação da fração PAR foram observadas primeiramente por MCCREE (1972) com respeito à nebulosidade, diante disso szEICZ (1974) correlacionou-a com a quantidade de água precipitável, encontrando grandes diferenças à medida que o vapor d'água aumentava na atmosfera. Este efeito é denominado de atenuação da radiação pela atmosfera (ROBINSON, 1966; MONTEITH, 1962; SELLERS, 1967 ; COULSON, 1975; GATES, 1980; MONTEITH \& UNSWORTH, 1990).

A existência de diferentes métodos para determinar a porção fotossinteticamente ativa para um objetivo singular reflete a pluralidade de soluções para um mesmo problema. É evidente que cada metodologia apresenta não só a visão do autor, como também os recursos disponíveis para - desenvolvimento do trabalho. Por exemplo BRITTON \& DODD (1976) e ASSIS \& MENDES (1989) estimaram a fração PAR em função somente da radiação global. STANHIL \& FUCHS (1976), ALMEIDA et al (1979), PEREIRA et al (1982), STIGTER \& MUSABILHA (1982), MACHADO et al (1985) e KARALIS (1989) fazem a estimativa da porção PAR em função da radiação global, da elevação solar ou transmissão atmosférica, enquanto outros 
autores como SURAQUI (1972), SZEICZ (1974), JUSTUS \& PARIS (1984), MCCREE (1984), HANSEN (1984), MEEK et al (1984), WEISS \& NORMAN (1985) e GUEYMARD (1989) utilizam o máximo de variáveis como espalhamento de Rayleigh, turbidez atmosférica, transmitância, nebulosidade, quantidade de vapor d'água na atmosfera, elevação solar, radiação global e infravermelho.

Se o objetivo for a identificação de um tipo ideal de metodologia, os modelos de HANSEN (1984), WEISS \& NORMAN (1985), JUSTUS \& PARIS (1985) e GUEYMARD (1989) são mais completos. Todavia estes ultimos modelos de estimativas por serem bastante complexos são de pouca adoção, justamente por exigir equipamentos sofisticados e de custos elevados. Se, porém deseja-se utilizar um método mais simples, os modelos de BRITTON \& DODD (1976), PEREIRA et al (1982), ASSIS \& MENDES (1989) são mais fáceis por envolverem somente medidas tomadas no campo com equipamentos convencionalmente utilizados em estações meteorológicas.

Como a penetração da radiação solar na atmosfera depende de todos estes fatores citados anteriormente, seria adequado estimar a taxa de radiação fotossinteticamente ativa em função da radiação no topo da atmosfera e da razão de insolação, que é uma função implícita daquelas variáveis citadas anteriormente. A radiação fotossinteticamente ativa seria então representada pela fórmula de Ångström-Prèscott, obtendo-se dois coeficientes de calibração (a e b) para o novo modelo. Este método foi utilizado por OMETTO (1968) para estimar a radiação global em Piracicaba. Desta forma, o modelo seria bastante simples e poderia ser utilizado em qualquer lugar do mundo, desde que fosse calibrado para o local escolhido.

Existem muitas informações acerca da PAR em função da variação do ângulo solar, nebulosidade e quantidade de vapor d'água na atmosfera, no entanto existem poucas referente ao efeito do tipo de nuvem. OMETTO et al (1971) 
estudando a transmissividade atmosférica da radiação solar dependente do tipo de cobertura, deparou com esta possibilidade e fez um estudo da radiação difusa para Piracicaba, utilizando a fórmula de Ångström-Prèscott.

LAUE \& DRUMMOND (1968) mediram a densidade de fluxo de radiação extra-terrestre nos comprimentos de onda acima de $200 \mathrm{~nm}$ e registraram uma intensidade solar de 1361 $\mathrm{W} / \mathrm{m}^{2}$. A fração de energia nas regiões ultravioleta e visível ficou em torno de $36 \%$ do fluxo radiante extra-terrestre. MCCREE (1972) comparou a radiação na faixa da PAR em nove diferentes fontes de luz e encontrou para luz natural os valores da razão de fluxo igual a $4,57 \mu \mathrm{E} / \mathrm{J}$ para radiação direta e difusa, e a de 4,24 $\mu \mathrm{E} / \mathrm{J}$ em condições de completa radiação difusa.

Para STANHILL \& FUCHS (1977) a medida rotineira da densidade de fluxo da radiação solar na faixa fotossinteticamente ativa, alcançando a superfície terrestre apresenta grandes dificuldades devido ao uso de filtros e sensores especiais. Por esta razão a PAR é freqüentemente estimada em função do fluxo de radiação solar global (Qg), usando um fluxo de densidade relativo $\eta=P A R / Q G$ como um fator de estimativa.

\subsubsection{Radiação Infravermelho próximo (NIR)}

Compreende comprimentos de onda característicos

da faixa entre 700 a $2800 \mathrm{~nm}$, responsável pelo aquecimento do ar, do solo e da água, onde grande parte desta radiação é absorvida por estes elementos (ROBINSON, 1966; COULSON, 1975), cuja distribuição é altamente sensível às variações atmosféricas. As nuvens, no geral, refletem e absorvem grande parte desta radiação; dependendo dos tipos de nuvens, estas podem refletir até $70 \%$, absorver $20 \%$ e transmitir somente $10 \%$ de toda radiação incidente sobre elas (SELLERS, 1965). o vapor d'água e outros constituintes da atmosfera interagem alterando a qualidade e quantidade da radiação. 


\section{MATERIAL E MÉTODOS}

\subsection{Caracteristicas Local e Instrumental}

\subsubsection{Localização}

As observações radiométricas foram conduzidas na Estação Agrometeorológica da Escola superior de Agricultura "Luiz de Queiroz", ESALQ-USP, Campus de Piracicaba, Estado de São Paulo, 22 $42^{\prime} \mathrm{S}, 47^{\circ} 38^{\prime} \mathrm{W}$ e $570 \mathrm{~m}$ de altitude. O experimento constou do registro contínuo de 211 dias das densidades de fluxo radiante global, Fotossinteticamente ativa e Infravermelho próximo, a $1,5 \mathrm{~m}$ acima da superfície do solo durante os meses de junho a dezembro de 1993, no período compreendido entre o nascer e o pôr do sol.

\subsubsection{Instrumental}

As medidas das densidade de fluxo radiante foram tomadas por dois Piranômetros EPS e por um sensor Quântico fotovoltaico (veja Tabela 1, página 15), acoplados a um registrador potenciométrico com 3 canais para registro contínuo.

Tabela 1: Sensores Utilizados nas observações radiométricas.

\begin{tabular}{l|l|l|l}
\hline \hline CARACTERISTICA & SENSOR Qg & SENSOR PAR & SENSOR NIR \\
\hline \hline MODELO & EPPLEY PSP & LI-190SB & EPPLEY PSP \\
SENSIBILIDADE & $9,05 \mathrm{mV} / \mathrm{kW} \cdot \mathrm{m}^{-2}$ & $5 \mathrm{mV} / \mathrm{mE} \cdot \mathrm{m}^{-2} \cdot \mathrm{s}^{-1}$ & $10,48 \mathrm{mV} / \mathrm{kW} \cdot \mathrm{m}^{-2}$ \\
ESPECTRO & $290 \mathrm{a} 2800 \mathrm{~nm}$ & $400 \mathrm{a} 700 \mathrm{~nm}$ & 700 a 2800 $\mathrm{nm}$ \\
FILTRO & WG 295 & RG 695 \\
ERRO & $\pm 5 \%$ & $\pm 5 \%$ & $\pm 5 \%$ \\
\hline \hline
\end{tabular}


- piranômetro Eppley é um sensor de energia radiante, constituído de junções quentes, em preto fosco e junções frias, em branco brilhante, situadas na face que recebe a radiação. A quantificação do fluxo radiante baseiase no efeito "Seebeck", ou seja, a diferença de potencial estabelecida entre as junçōes quentes e frias é função da desigualdade de temperatura entre elas, que é determinado pelas características de absortância do material em relação à radiação solar. As junções que compõem o elemento sensível ficam envoltas por uma cúpula de vidro hermeticamente fechada. A sensibilidade do piranômetro é compatível com todo espectro da energia radiante, tanto global como difusa e é uma função das propriedades e números dos termopares, e ainda das características físicas da cúpula.

- filtro WG-295 é uma cúpula de vidro claro e transparente à radiação entre 290 a $2800 \mathrm{~nm}$, o qual é empregado para determinar a radiação global. o filtro RG-695 é usado para separar a região do infravermelho próximo da faixa global. Por abranger a faixa espectral de 700 a 2800 $\mathrm{nm}$, tem sido bastante usado e recomendado internacionalmente para esta finalidade.

A densidade de fluxo de fótons fotossintéticos foi determinada pelo sensor Quântico LI 190SB, que opera na faixa de 400 a $700 \mathrm{~nm}$.

Também utilizou-se um "temporizador" para ligar

- registrador ao nascer e desligar-se ao pôr do sol.

Os valores espectrais de radiação foram decodificados pela integração diária e horária das curvas registradas, utilizando-se uma mesa digitalizadora configurada ao software AUTOCAD.

\subsection{Metodologia}

\subsubsection{Dados coletados}

Aos dados obtidos através do Piranômetro com filtro RG-695 aplicou-se o fator de correção de DRUMMOND \& 
ROCHE $^{3}$ (1965) igual a 0,91, conforme COULSON (1975), SZEICZ (1974) e STIGTER \& MUSABILHA (1982), para minimizar o acréscimo de temperatura do filtro pela absorção da radiação solar, e consequiente aquecimento da cúpula interna e aparente aumento da sensibilidade do equipamento.

os dados registrados e integrados diariamente durante os sete meses foram separados em dias com céu nublado $(\mathrm{n} / \mathrm{N} \leq 0,1)$, dias com céu parcialmente nublado $(0,1<\mathrm{n} / \mathrm{N}<0,9)$ e dias com céu límpido $(n / N \geq 0,9)$. Os dados de insolação do período foram fornecidos pelo Departamento de Física e Meteorologia da ESALQ/USP. Selecionou-se 7 dias com céu totalmente limpo, e 7 com céu totalmente nublado fez-se a integração horária para avaliar a variação média das densidades de fluxo de radiação.

As unidades das densidades de fluxo radiante foram determinadas em $\mathrm{W} / \mathrm{m}^{2}$ e $\mathrm{MJ} / \mathrm{m}^{2}$. dia para a radiação global e a radiação infravermelho próximo; e em $\mu \mathrm{E} / \mathrm{m}^{2}$.s e $\mu \mathrm{E} / \mathrm{m}^{2}$.dia (densidade de fluxo de fótons) para a radiação fotossinteticamente ativa. O fator de MCCREE (1972), 4,57 $\mu \mathrm{E} / \mathrm{J}$ para céu Iimpo e 4,24 $\mu \mathrm{E} / \mathrm{J}$ para céu totalmente nublado foi aplicado para converter a PAR em $\mathrm{W} / \mathrm{m}^{2}$ e $\mathrm{MJ} / \mathrm{m}^{2}$.dia, sendo que para os dias parcialmente nublado utilizou-se uma média dos dois valores, ou seja $4,40 \mu \mathrm{E} / \mathrm{J}$.

\subsubsection{Dados calculados}

A radiação diária no topo da atmosfera foi estimada utilizando-se a seguinte fórmula:

$$
Q_{0}=\int_{t_{n}}^{t_{p}} J_{0}\left(\frac{\bar{D}}{D}\right)^{2} \cos z d t \cdot . . . . \cdot
$$

tn e tp são respectivamente o tempo ao nascer e ao pôr do

${ }^{3}$ DRUMMOND, A. J. \& ROCHE, J. J., 1965. Corrections to be applied to measurements made with Eppley (and other) spectral radiometers when used with scott colored glass filters. Journal of Applied Meteorology. 4:741-744. 
sol, Jo=1360 W/m² corresponde à constante solar.

- fator dependente da distância Terra-sol é calculado pela fórmula de SPENCER (1971):

$$
\begin{aligned}
\left(\frac{\bar{D}}{D}\right)^{2}= & 1,00011+0,034221 \cos X+0,00128 \operatorname{sen} X+ \\
& +0,000719 \cos 2 X+0,000077 \operatorname{sen} 2 X \\
& \text { Os valores de } \mathbf{x} \text { são calculados pela expressão: }
\end{aligned}
$$

$$
X=\frac{2 \pi \text { (dia juliano-1) }}{365} \text {. . . . . . }
$$

o ângulo zenital foi calculado pela fórmula: $z=\arccos (\operatorname{sen} \phi \cdot \operatorname{sen} \delta+\cos \phi \cdot \cos \delta \cdot \cos H) \cdot \cdot \cdot$ (4)

o ângulo horário ao nascer do sol corresponde:

$$
H=\arccos (-\tan \phi \cdot \tan \delta) \text {. . . . . }
$$

A hora ao pôr do sol corresponde a:

$$
t_{p}=\frac{H}{15}+12 \text {. . . . . . . . . }
$$

o comprimento astronômico do dia é dado por:

$$
N=\frac{2 H}{15} \cdot \cdot \cdot \cdot \cdot \cdot \cdot \cdot \cdot \cdot \cdot \cdot
$$

A hora ao nascer do sol corresponde a:

$$
t_{n}=t_{p}-N \cdot \cdot \cdot \cdot \cdot \cdot \cdot \cdot \cdot \cdot
$$

A declinação solar foi extraída do Anuário Astronômico.

A elevação solar é estimada em função do ângulo zenital:

$$
\beta=(90-z) \cdot . \cdot \cdot \cdot \cdot \cdot \cdot \cdot
$$

A integração horária dos dados corresponde ao horário solar

\subsubsection{Correlações}

A radiação fotossinteticamente ativa, coletada diariamente pelo método direto, foi correlacionada com a radiação global independente das condições atmosféricas; com a radiação global em função da razão de insolação (n/N); com 
a radiação global sob três diferentes classes de razões de insolação e com a radiação global em função do ângulo de elevação solar ( $(\beta)$.

Para fins comparativos, correlacionou-se a PAR obtida pelo método indireto, $P A R=(Q g-N I R)$ com a radiação global sem levar em conta as condições atmosféricas.

Buscando estimativas mais amplas, PAR, NIR e Qg foram correlacionadas conjuntamente com a radiação no topo da atmosfera (QO) e razão de insolação $(\mathrm{n} / \mathrm{N})$. A radiação ultravioleta foi determinada a partir de resíduos da radiação global menos o somatório das radiações fotossinteticamente ativa e a infravermelho próximo, Uv=Qg-(PAR+NIR) . 


\section{RESULtados E DISCUSSÃo}

\subsection{Resultados obtidos com dados diários}

\subsubsection{Relação da PAR/Qg}

A análise dos dados obtidos no período de junho a dezembro de 1993, correspondente a 211 dias aproveitados, permitiram estabelecer várias relações. A radiação global variou de 1,3 a $31,4 \mathrm{MJ} / \mathrm{m}^{2}$.dia com média de 15,8 $\mathrm{MJ} / \mathrm{m}^{2}$.dia; NIR variou de 0,4 a $15,5 \mathrm{MJ} / \mathrm{m}^{2}$.dia, média de $7,3 \mathrm{MJ} / \mathrm{m}^{2}$. dia e PAR variou de 3,1 a $58,6 \mathrm{E} / \mathrm{m}^{2}$.dia, média de $31,1 \mathrm{E} / \mathrm{m}^{2}$.dia.

A regressão linear correspondente à densidade de fluxo de fótons fotossintéticos em função da radiação global, independente de qualquer condição atmosférica produziu um resultado satisfatório visto que $R^{2}=0,978$ e a razão $\mathbf{P A R} / Q g=1,95 \mu \mathrm{E} / \mathrm{J}$ (veja Figura 3, página 21). Este resultado mostrou-se menor que $2,23 \mu \mathrm{E} / \mathrm{J}$ encontrado no sul do Brasil por ASSIS \& MENDEZ (1989), mas tornou-se próximo a $1,91 \mu \mathrm{E} / \mathrm{J}$ encontrado por MEEK et al (1984) em Phoenix, também foi menor que 2,04 $\mu \mathrm{E} / \mathrm{J}$ determinado em Fresno por HOWELL \& MEEK (1983). Segundo estes autores, estas variações são atribuídas às condições atmosféricas diversas como nebulosidade, água precipitável e também aos diferentes modelos de estimativas.

Os dados foram separados em 3 diferentes classes de razão de insolação, conforme a nebulosidade. Em 30 dias com razão de insolação abaixo de 0,11, fez-se uma análise de regressão linear simples, PAR $\left(\mathrm{MJ} / \mathrm{m}^{2}\right.$.dia) em função de $\mathrm{gg}$. Obteve-se a seguinte equação PAR=0,496Qg com $R^{2}=0,991$ (veja Figura 4, página 22). 


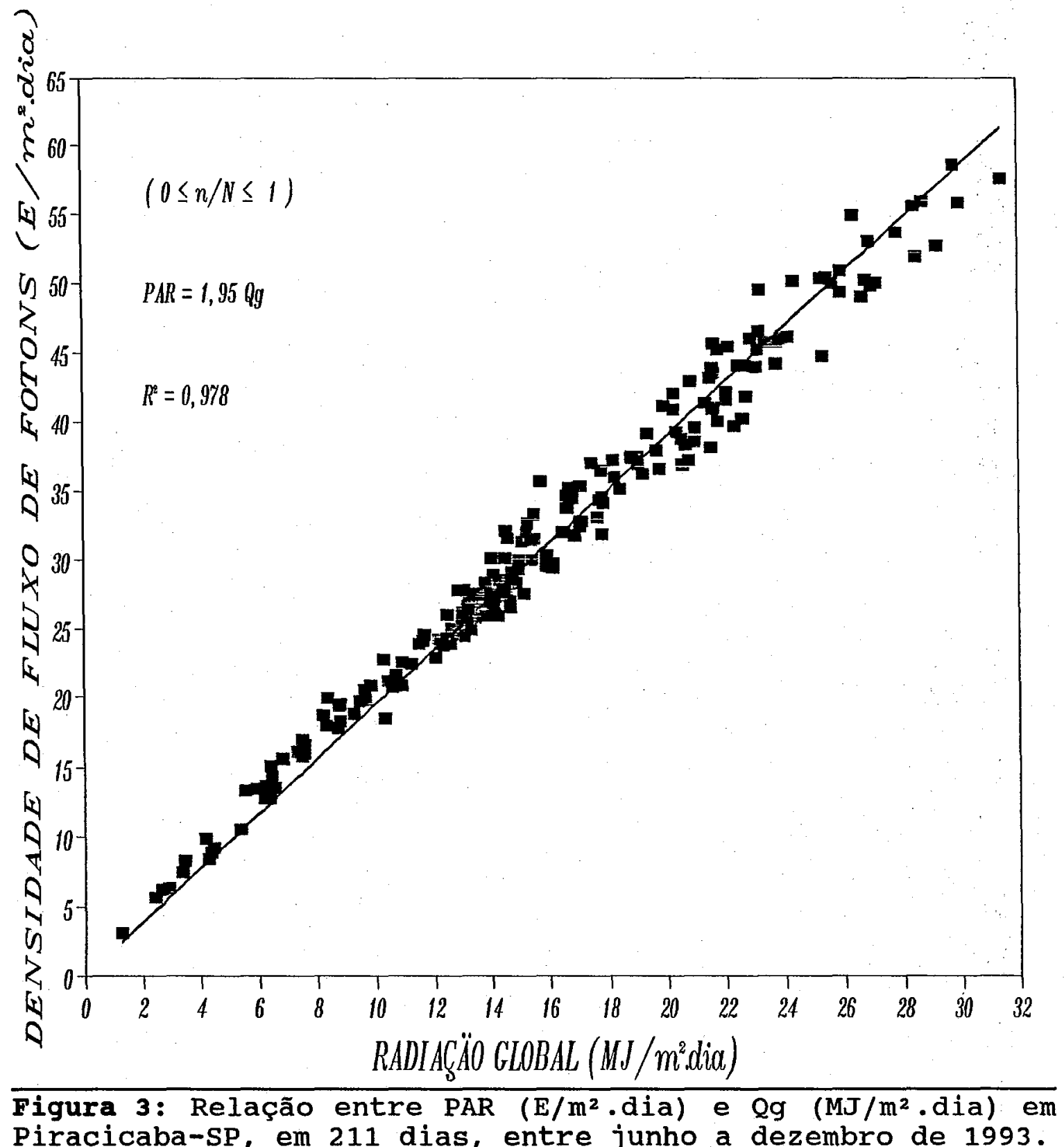

A estimativa obtida por regressão linear simples para a radiação fotossinteticamente ativa (PAR) em função da radiação global (Qg), em 146 dias com razão de insolação entre 0,1 a 0,9 , foi $P A R=0,429,9 g$ e $R^{2}=0,965$ (veja Figura 5, página 23). 


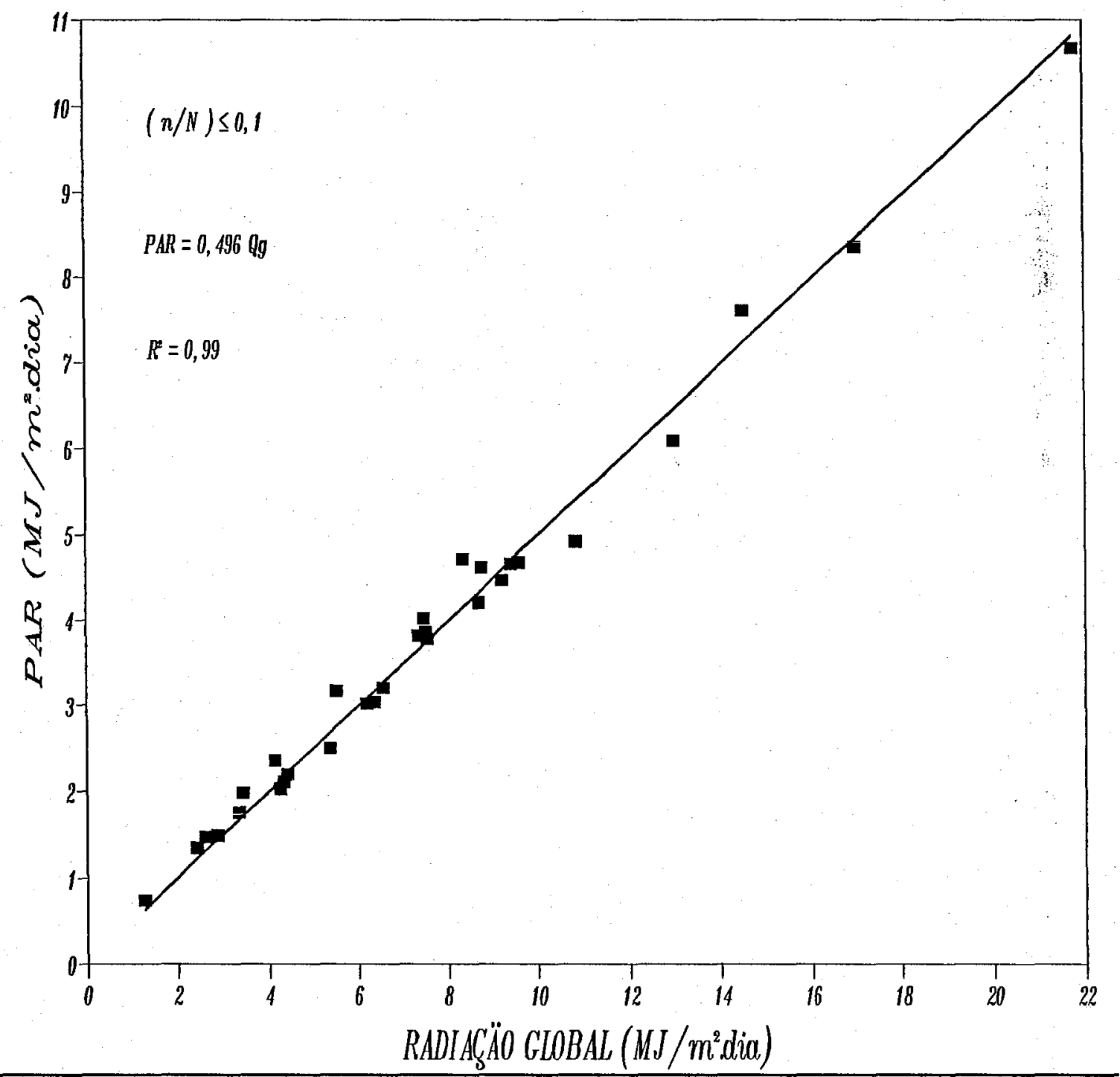

Figura 4: Relação entre PAR (MJ/m².dia) e $\mathrm{Qg}\left(\mathrm{MJ} / \mathrm{m}^{2}\right.$.dia) em Piracicaba-SP para 30 dias com céu completamente nublado, observados no periodo de junho a dezembro de 1993.

A relação PAR em função de $Q 9$, em 35 dias com razão de insolação acima de 0,89 produziu a equação linear $\mathbf{P A R}=0,417 \mathrm{Qg}$ e $\mathbf{R}^{2}=0,989$ (veja Figura 6, página 24).

Grandes variações foram observados, na faixa de 295 a $695 \mathrm{~nm}$, por STIGTER \& MUSABILHA (1982) em Dar es Salaam (Tanzânia), $\eta$ igual a 0,51 para dias claros, e 0,63 sob condições nubladas. 


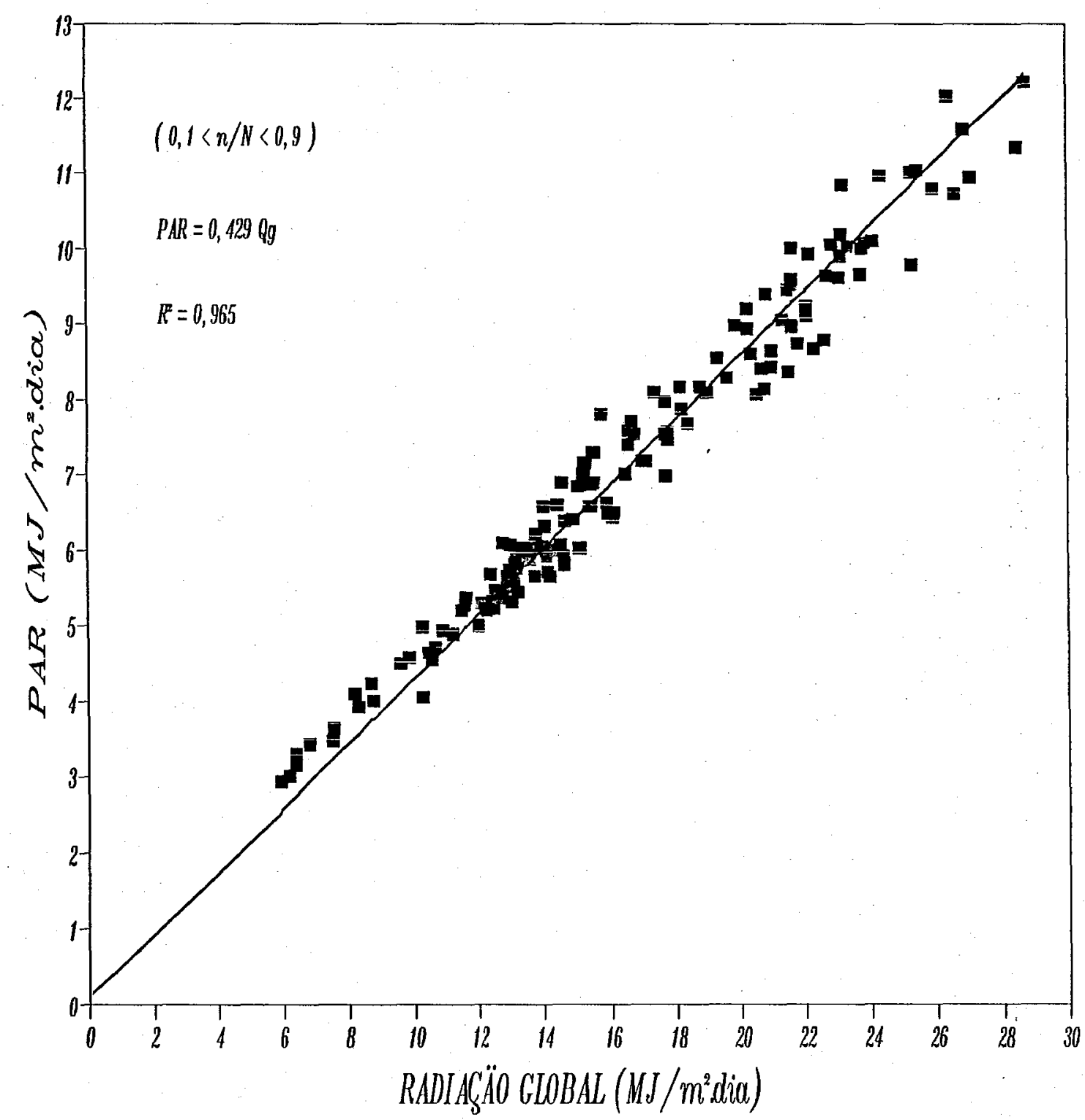

Figura 5: Relação entre PAR e Qg em Piracicaba-SP, para 146 dias com razão de insolação entre 0,1 e 0,9 no período de junho a dezembro de 1993. 


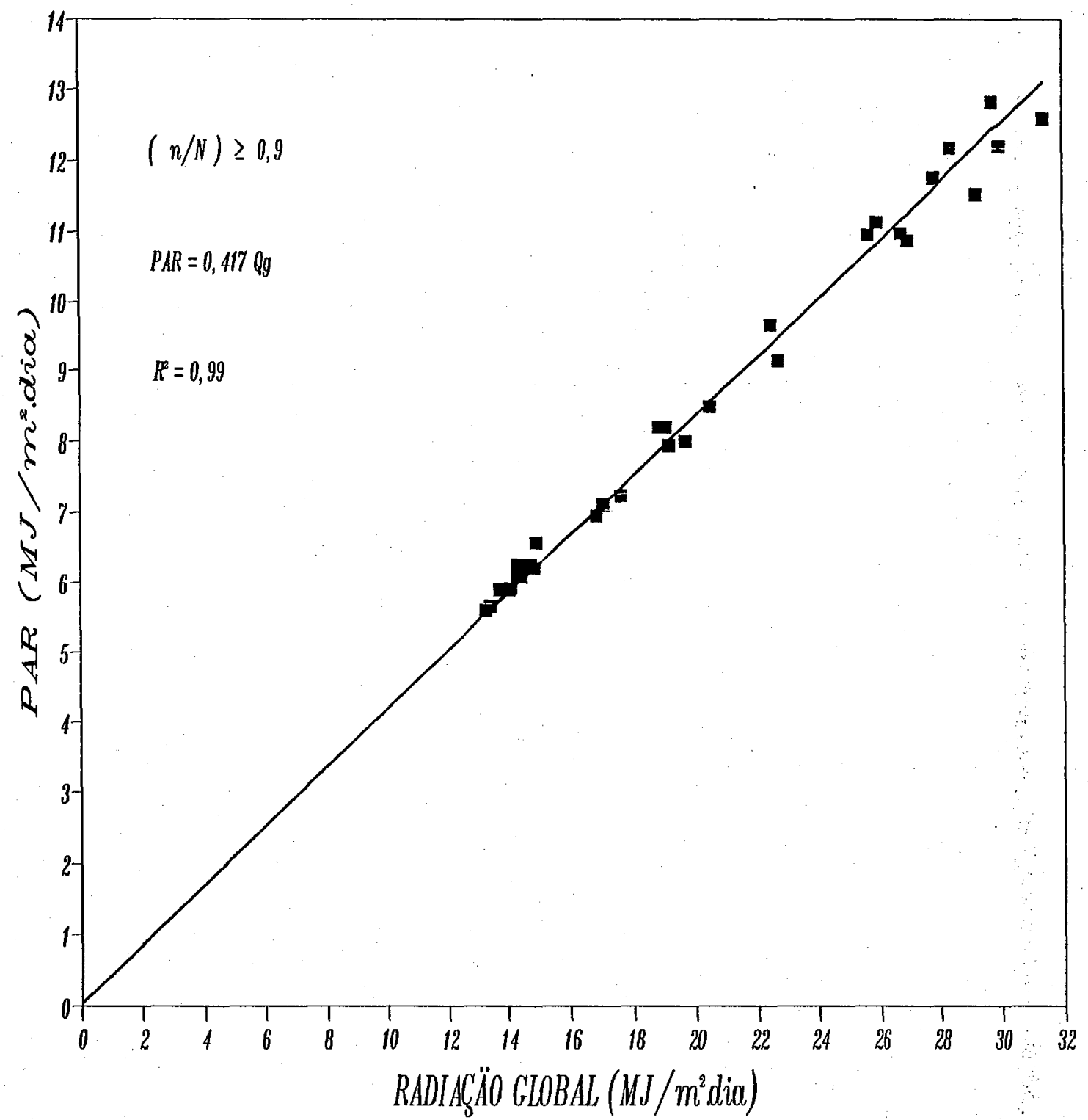

Figura 6: Relação entre PAR e Qg em Piracicaba-SP para 35 dias completamente límpidos de junho a dezembro de 1993. 


\subsubsection{Relação PAR/Qg em função de $n / N$}

A fração fotossinteticamente ativa PAR/Qg analisada por regressão linear, em função da razão de insolação $(n / N)$, produziu a equação $\operatorname{PAR}=Q g[0,501-0,102(n / N)]$ e $R^{2}=0,798$ (veja Figura 7, página 26) comprovando os resultados anteriores obtidos para diferentes razões de insolação.

Analisando os resultados anteriores, baseados na razão de insolação, nota-se que a fração $\eta$ é inversamente proporcional à razão de insolação.

SZEICZ (1974) e MONTEITH \& UNSWORTH (1990) consideram a fração PAR na ordem de $50 \%$ da radiação global medida por um radiômetro convencional, embora muitos outros autores tenham relatado razōes da ordem de $44 \%$ a $69 \%$ (BRITTON \& DODD, 1976; PEREIRA et al, 1982; HOWELL et al, 1983; ASSIS \& MENDES, 1989). Tomando-se valores relativos médios de junho a dezembro (veja Tabela 2 , página 25), as variações de $\eta$ ficaram entre $0,43 \pm 0,03$ a $0,45 \pm 0,05$, em que a média do período estudado foi de $0,44 \pm 0,04$ para uma razão de insolação média igual a 0,56 . Os meses de agosto e novembro foram atípicos no ano de observação dos dados, portanto notase aí um contraste entre estes meses quanto à razão $\eta$.

Tabela 2: Razões de insolação médias, densidades de fluxos radiante médios de $Q 9$, PAR e NIR, fração $\eta=P A R / Q g$ os desvios $(\sigma)$ médios mensais de $\eta$.

\begin{tabular}{|c|c|c|c|c|c|c|}
\hline \multirow[t]{2}{*}{ MÊS } & \multirow[t]{2}{*}{$\mathrm{n} / \mathrm{N}$} & Qg & PAR & NIR & \multirow[t]{2}{*}{$\eta$} & \multirow[t]{2}{*}{$\sigma$} \\
\hline & & \multicolumn{3}{|c|}{$\left(\mathrm{MJ} / \mathrm{m}^{2} \cdot \mathrm{dia}\right)$} & & \\
\hline $\begin{array}{l}\text { JUN } \\
\text { JUL } \\
\text { AGO } \\
\text { SET } \\
\text { OUT } \\
\text { NOV } \\
\text { DEZ }\end{array}$ & $\begin{array}{l}0,62 \\
0,66 \\
0,61 \\
0,43 \\
0,55 \\
0,65 \\
0,44\end{array}$ & $\begin{array}{l}11,7 \\
12,2 \\
14,0 \\
13,5 \\
18,5 \\
22,6 \\
18,3\end{array}$ & $\begin{array}{l}5,1 \\
5,3 \\
6,0 \\
5,9 \\
8,0 \\
9,6 \\
8,1\end{array}$ & $\begin{array}{r}5,5 \\
5,7 \\
6,5 \\
6,3 \\
8,5 \\
10,8 \\
8,2\end{array}$ & $\begin{array}{l}0,45 \\
0,44 \\
0,44 \\
0,45 \\
0,44 \\
0,43 \\
0,46\end{array}$ & $\begin{array}{l}0,03 \\
0,03 \\
0,04 \\
0,05 \\
0,03 \\
0,03 \\
0,04\end{array}$ \\
\hline MÉDIA & 0,56 & 15,8 & 6,9 & 7,3 & 0,44 & 0,04 \\
\hline
\end{tabular}




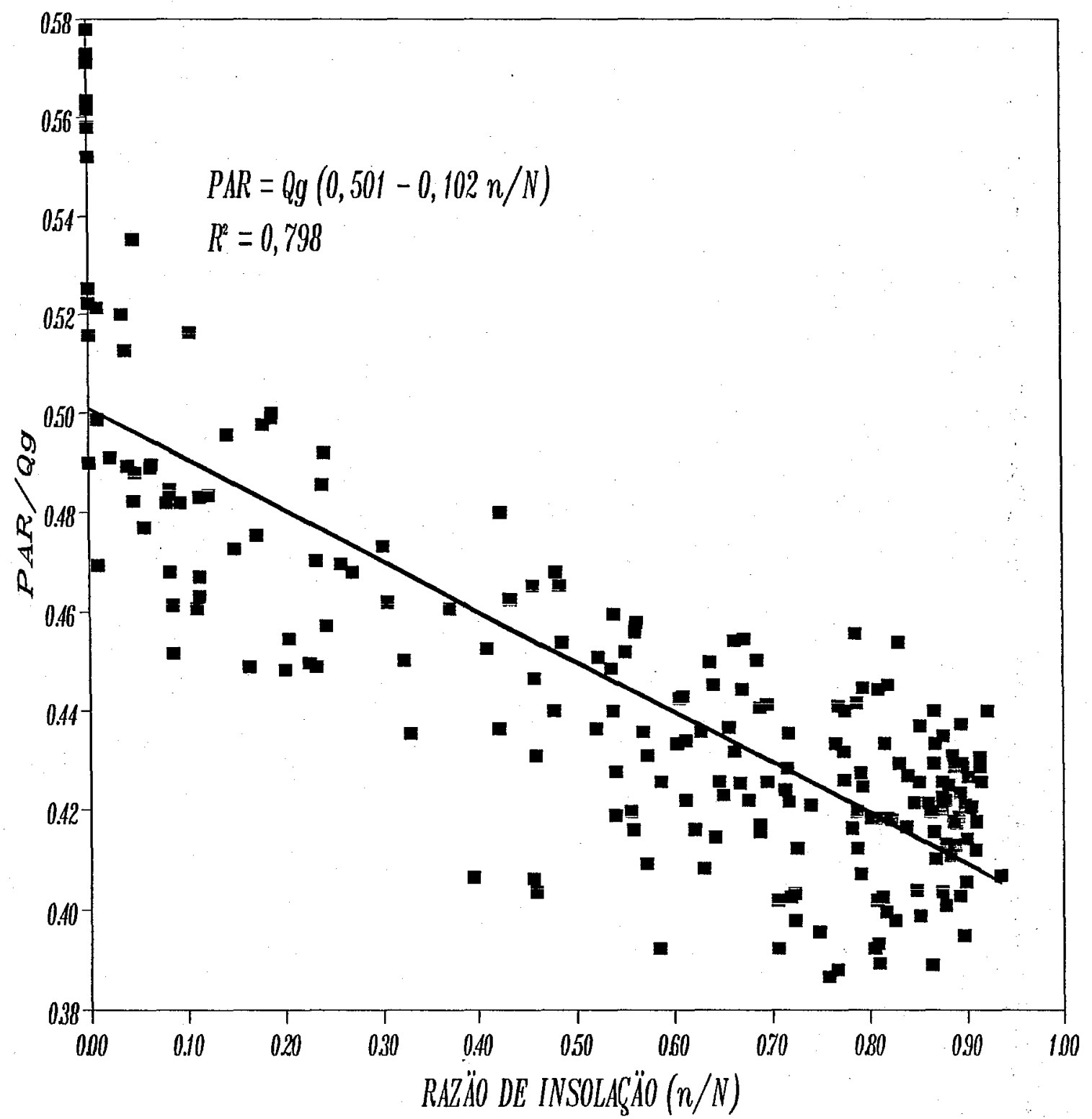

Figura 7: Relação PAR/Qg em função de (n/N) para PiracicabaSP, durante 211 dias no período de junho a dezembro de 1993 . 
STANHILL \& FUCHS (1977) encontraram valores médios diários para $\eta=0,47 \pm 0,07$ e $\eta=0,49 \pm 0,02$ para valores médios mensais; assim sugeriram uma relação constante igual a 0,5 na qual seria usada para elevações solar acima de $10^{\circ}$.

\subsubsection{Relação entre (Qg-NIR) em função de $Q g$}

A radiação fotossinteticamente ativa obtida pelo método indireto, fazendo-se PAR=Qg-NIR, foi correlacionada com a radiação global para fins comparativos a qual resultou na equação [Qg-NIR]=0,533gg e $R^{2}=0,987$ (veja Figura 8, página 28).

Nota-se portanto um erro de aproximadamente $10 \%$ em relação ao método direto. Esta série de valores encontrados para $\eta$ são atribuídos em parte às diferentes faixas limites escolhidas para definir a PAR, e em outra pela diversidade entre os métodos usados para avaliá-la.

\subsubsection{Relaçōes $\mathrm{Qg}$, PAR e NIR em função de $Q 0$ e $n / N$}

Tomando-se os valores estimados da radiação no topo da atmosfera (QO), os valores da razão de insolação(n/N) e os valores de $\mathrm{Qg}$, PAR e NIR obtidos no período, fez-se diferentes correlações.

A relação $Q g / Q \circ$ em função de $n / N$ resultou em $Q g=00[0,224+0,466(\mathrm{n} / \mathrm{N})]$ e $\mathbf{R}^{2}=0,796$ (veja Figura 9, página 29). Os coeficientes estimados nesta equação se aproximam aos obtidos por OMETTO (1968), $Q g=Q \circ[0,26+0,51(\mathrm{n} / \mathrm{N})]$, mas com pouca diferença nos coeficientes linear e angular, isto devese provavelmente às condições de tempo entre a pesquisa em questão e a pesquisa conduzida por OMETTO (1968), bem como ao grande número de observações realizadas por aquele autor. 


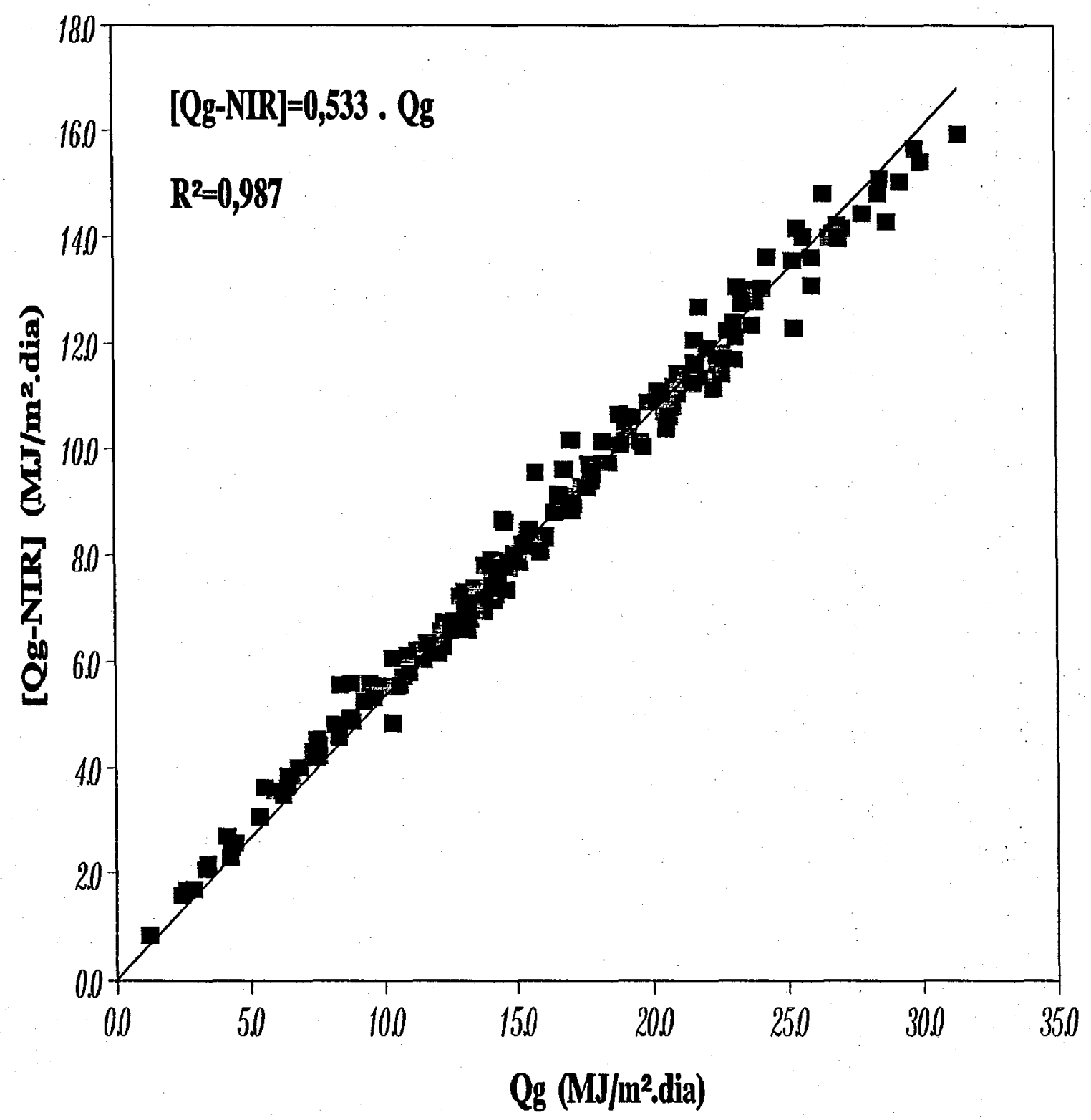

Figura 8: Relação da PAR obtida pelo método indireto (Qg-NIR) em função da radiação global para Piracicaba-sP, em 211 dias no período de junho a dezembro de 1993. 


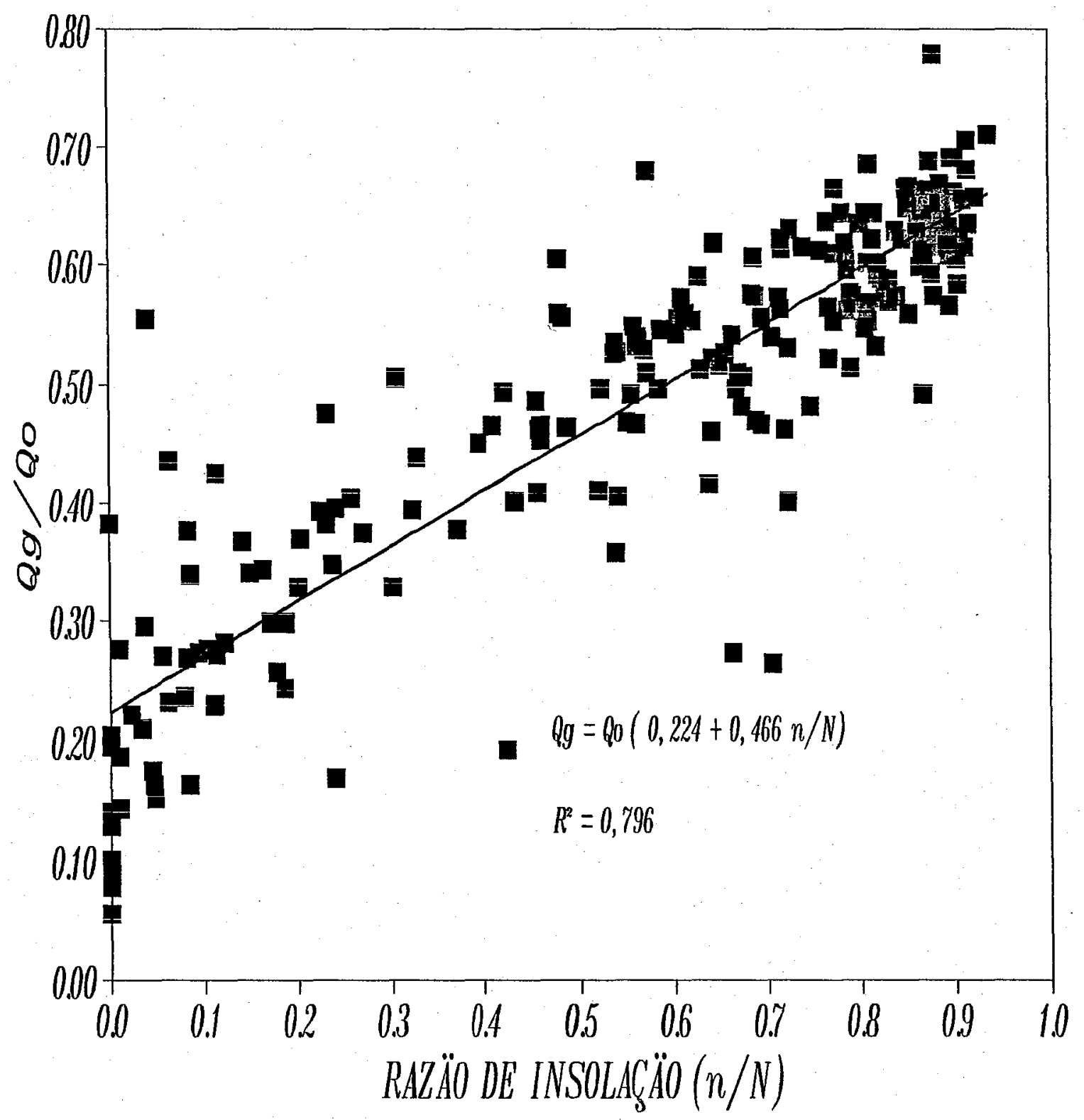

Figura 9: Radiação global em função da radiação no topo da atmosfera (QO) e da razão de insolação (n/N) para PiracicabaSP, no período de junho a dezembro de 1993 . 
A análise de regressão da fração PAR/Q0 em função da razão de insolação ( $n / N)$ produziu a equação $\operatorname{PAR}=Q \circ[0,498+0,816(\mathrm{n} / \mathrm{N})]$ e $R^{2}=0,734$, QO é dado em $\mathrm{MJ} / \mathrm{m}^{2} . \mathrm{dia}$ e PAR em $\mathrm{E} / \mathrm{m}^{2}$.dia. A Figura 10 na página 31 mostra uma grande dispersão de dados, principalmente quando a razão de insolação tende a 0 . Isto está ligado diretamente aos diferentes tipos de nuvens que predominam durante o dia, motivos estes também explicados por OMETTO (1968) e VIANELLO \& ALVES (1991) quando estudaram as relações $Q 9 / 20^{\circ}$ e $n / N$, em que cada gênero de nuvem predomina uma absorção diferente na faixa infravermelho devido à sua espessura e quantidade de vapor d'água na sua constituição.

A Figura 11, página 32, mostra uma dispersão semelhante à figura anterior, cuja relação NIR/Qo em função da razão de insolação $(n / N)$ foi estimada pela equação NIR $=00[0,091+0,239(\mathrm{n} / \mathrm{N})]$, que também se deve aos diferentes tipos predominantes de cobertura do céu e à transmissividade atmosférica local.

\subsection{Resultados obtidos com dados horários}

4.2.1 Distribuição espectral horária média

Tomou-se os dados médios horários de Qg, PAR e NIR, em $\mathrm{W} / \mathrm{m}^{2}$, durante 14 dias, sendo 7 dias com céu limpo e 7 dias com céu nublado e obteve-se uma distribuição horária média para as duas diferentes condições atmosféricas. 


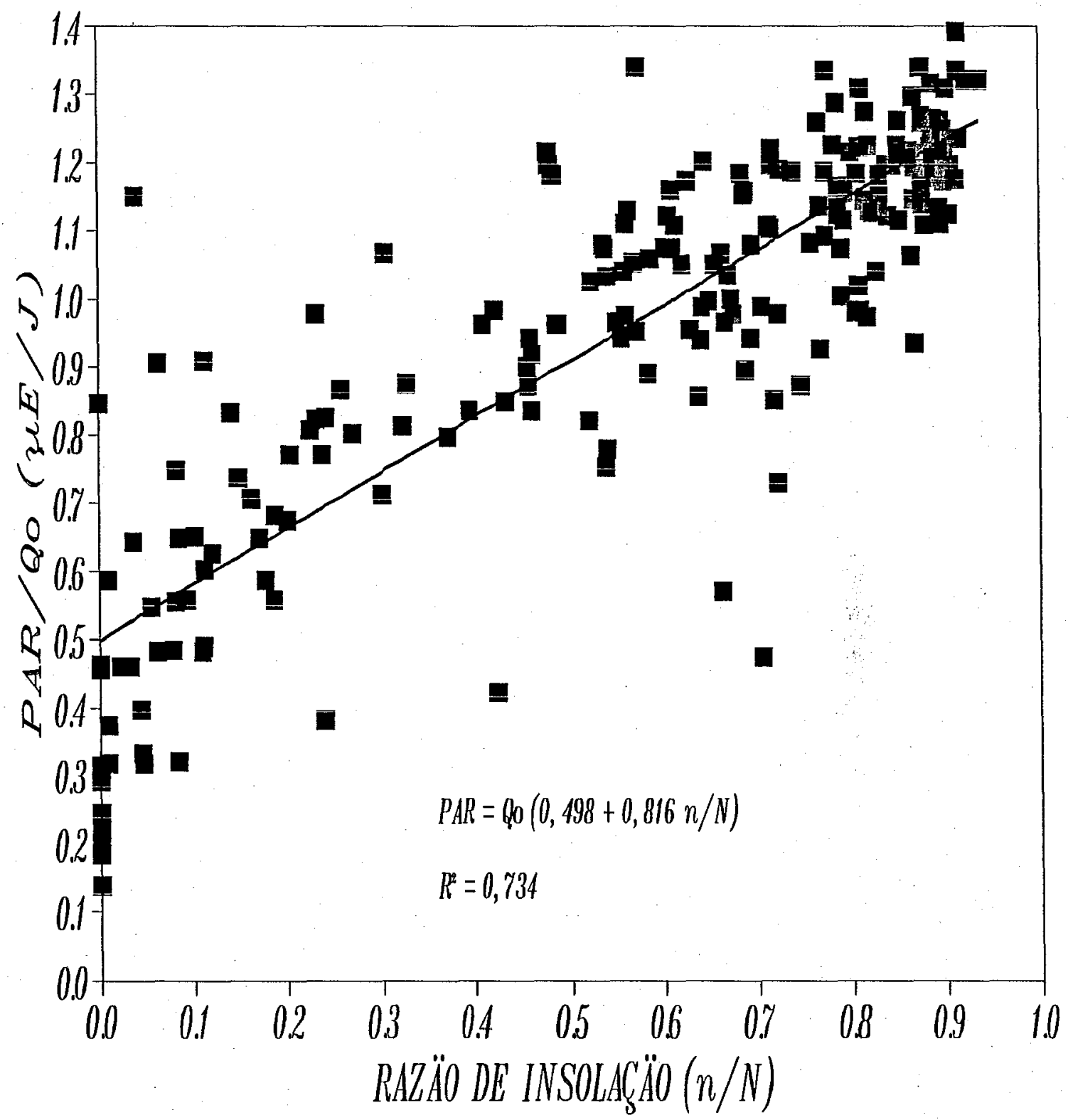

Figura 10: Relação entre PAR e Qo em função da razão de insolação para Piracicaba-SP, durante 211 dias no período de junho a dezembro de 1993. 


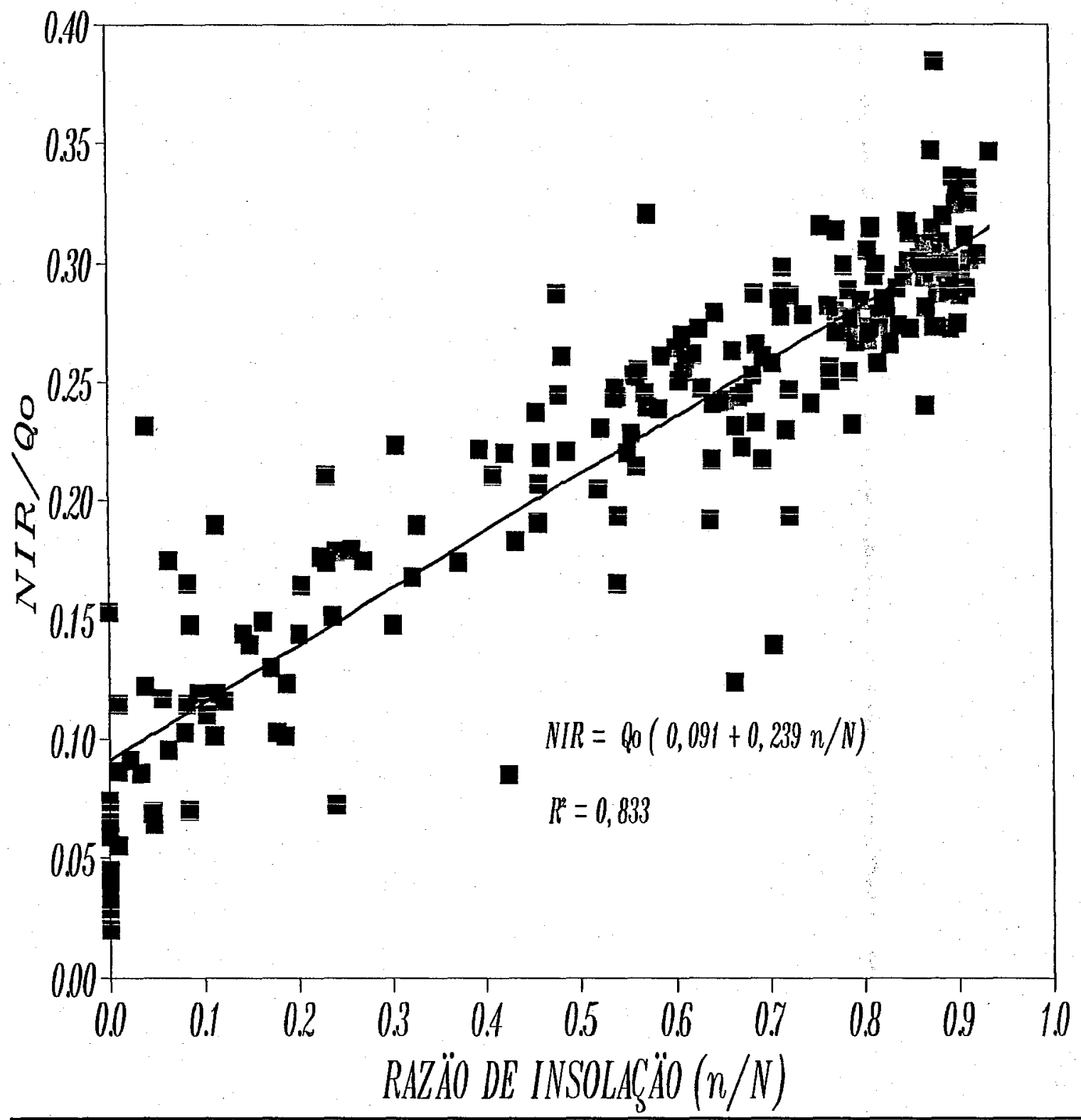

Figura 11: Relação entre NIR e Qo em função da razão de insolação para Piracicaba-SP, em 211 dias observados durante - período de junho a dezembro de 1993. 
A Figura 12, página 34 e a Tabela 3, página 35 mostram a distribuição para um dia com céu limpo. Nota-se, portanto que a fração $\eta$ é ligeiramente maior entre 6:00 e 8:00 horas e entre 16:00 e 18:00 horas. Outra observação importante é que a radiação fotossinteticamente ativa permanece maior que a radiação infravermelho próximo nestes mesmos intervalos horáxios, devido ao maior caminho ótico e à grande quantidade de vapor d'água que a radiação solar tem que atravessar neste período do dia. No entanto, à medida que a altura solar se eleva há um aumento acentuado da radiação infravermelho próximo, uma vez que o caminho ótico é menor ao meio dia.

A Tabela 4 na página 35 e a Figura 13 na página 36 mostram a distribuição média horária para um dia nublado, onde se verifica que, quando há nuvens a radiação fotossinteticamente ativa permanece ligeiramente maior que a radiação infravermelho próximo, devido à grande quantidade de vapor d'água na atmosfera, proporcionando o aumento da fração PAR dentro da radiação global.

Quanto à radiação ultravioleta, esta ficou praticamente constante, em torno de $9 \%$, independente das condições de cobertura do céu. Todavia como já foi dito anteriormente, a observação do ultravioleta através da diferença Qg-(NIR+RAR) não permite grande precisão. Para uma melhor análise desta fração da radiação seria necessário o uso de equipamento específico.

4.2.2 Relações PAR/Qg em função da elevação solar (B) Além da distribuição espectral horária também estimou-se por regressão linear as variações de $\eta$ ao longo do dia em função da elevação solar (B) para dias claros e para dias nublados. Os resultados das análises mostram as equações lineares, em que $\operatorname{PAR}=\operatorname{Qg}[0,5117-0,00185(\beta)]$ foi obtida para os dias com céu limpo e $P A R=Q g[0,5908-0,00076(\beta)]$ para os dias com céu nublado. 


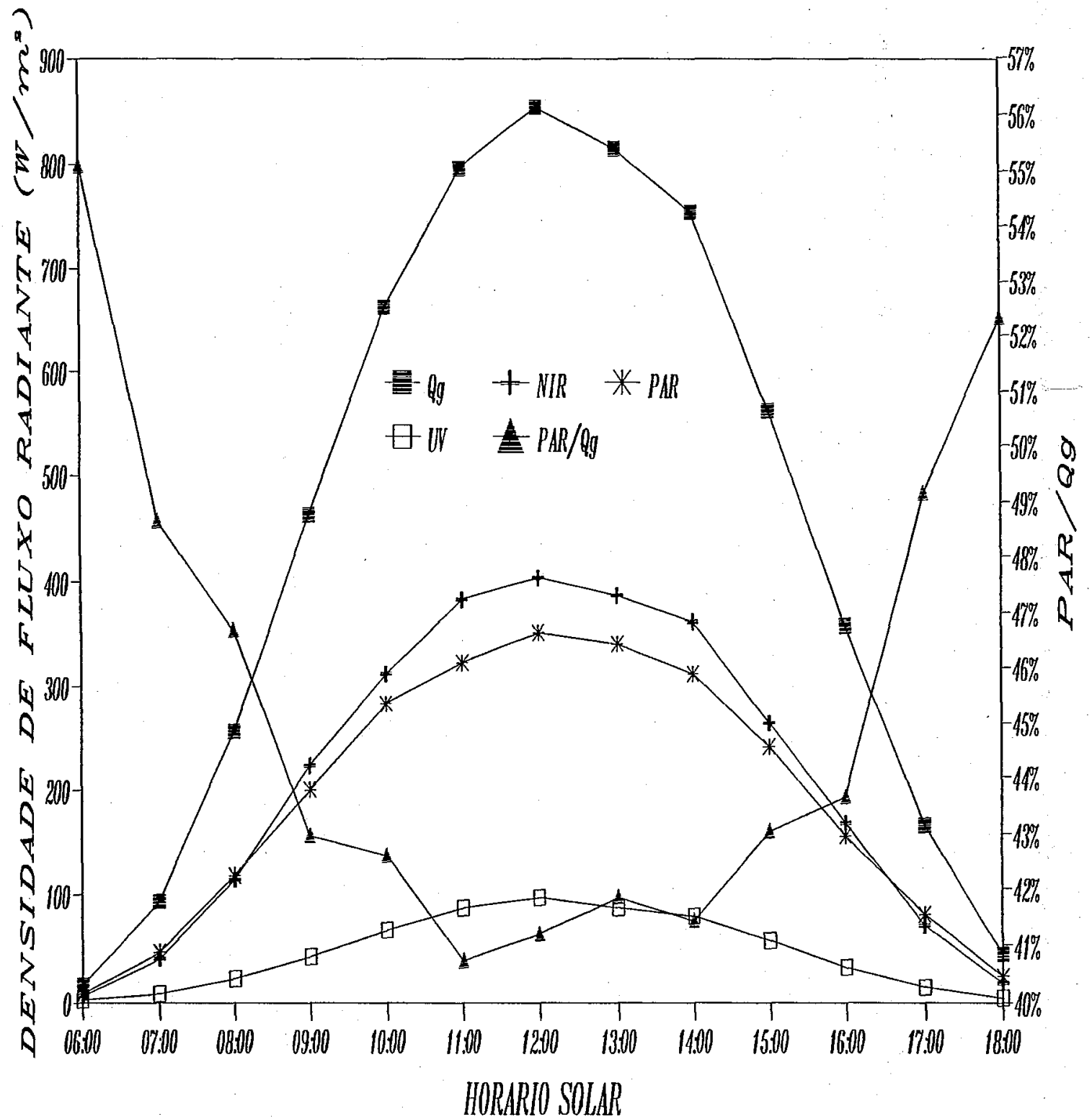

Figura 12: Evolução horária da distribuição espectral da radiação solar e da fração fotossinteticamente ativa para dia com céu completamente limpo (média de 7 dias). 
Tabela 3: Distribuição espectral horária média das densidades de fluxos $Q g$, PAR, NIR e UV, e respectivas porções $(\eta=P A R / Q g$, $\iota=N I R / Q g$ e $\nu=U V / Q g)$ para um dia com céu completamente limpo.

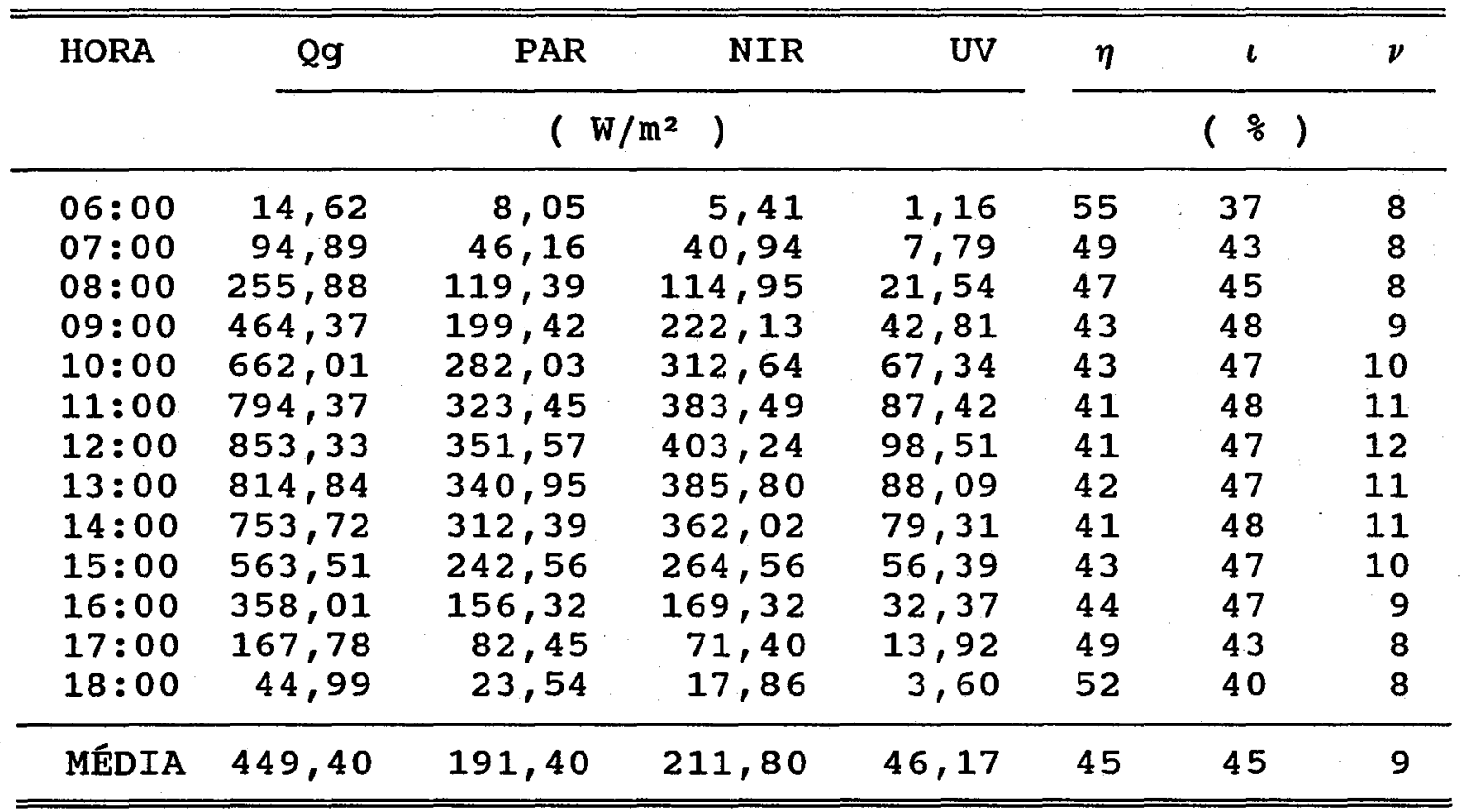

Tabela 4: Distribuição espectral horária média das densidades de fluxos Qg, PAR, NIR e UV, e respectivas porções para um dia com céu completamente nublado.

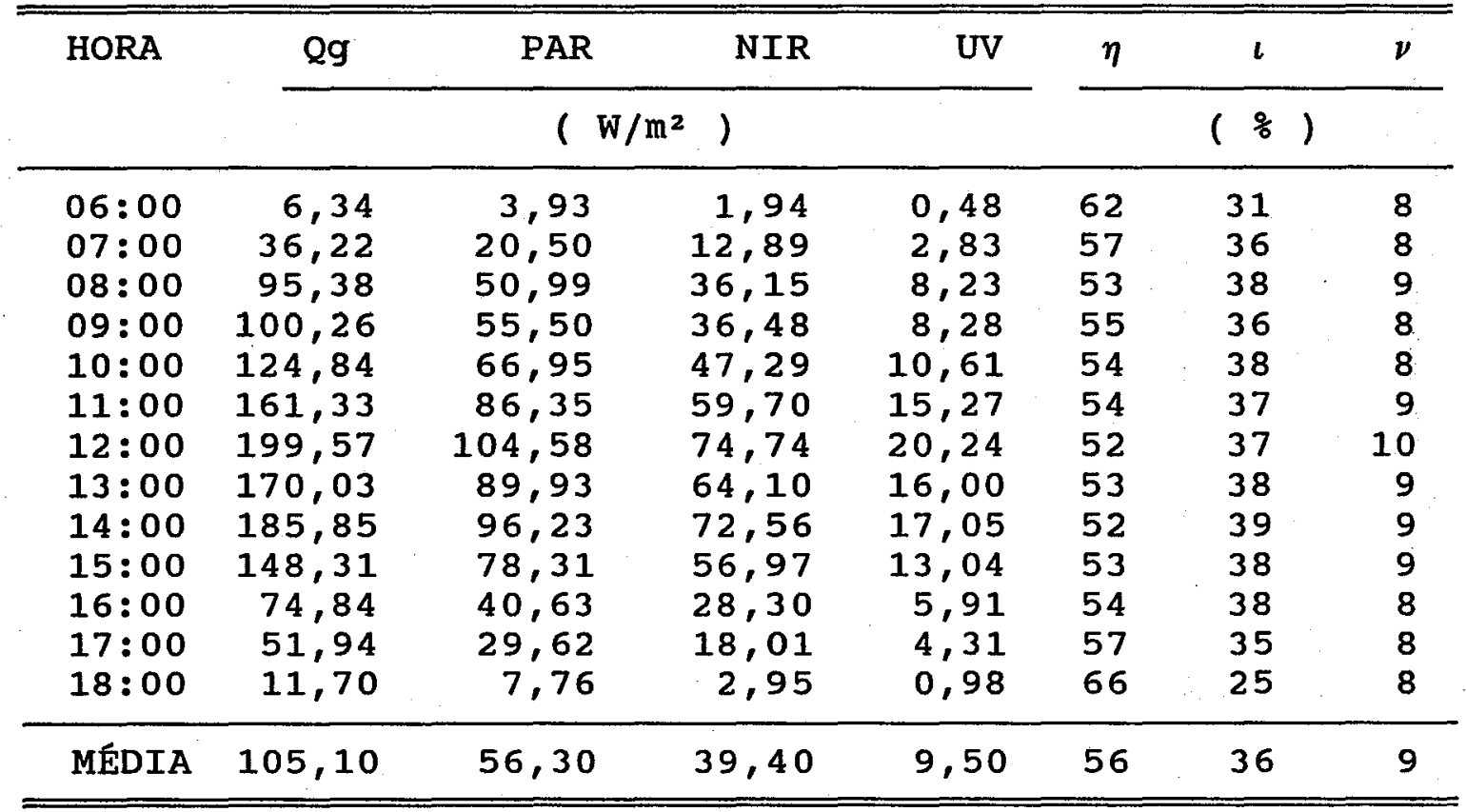




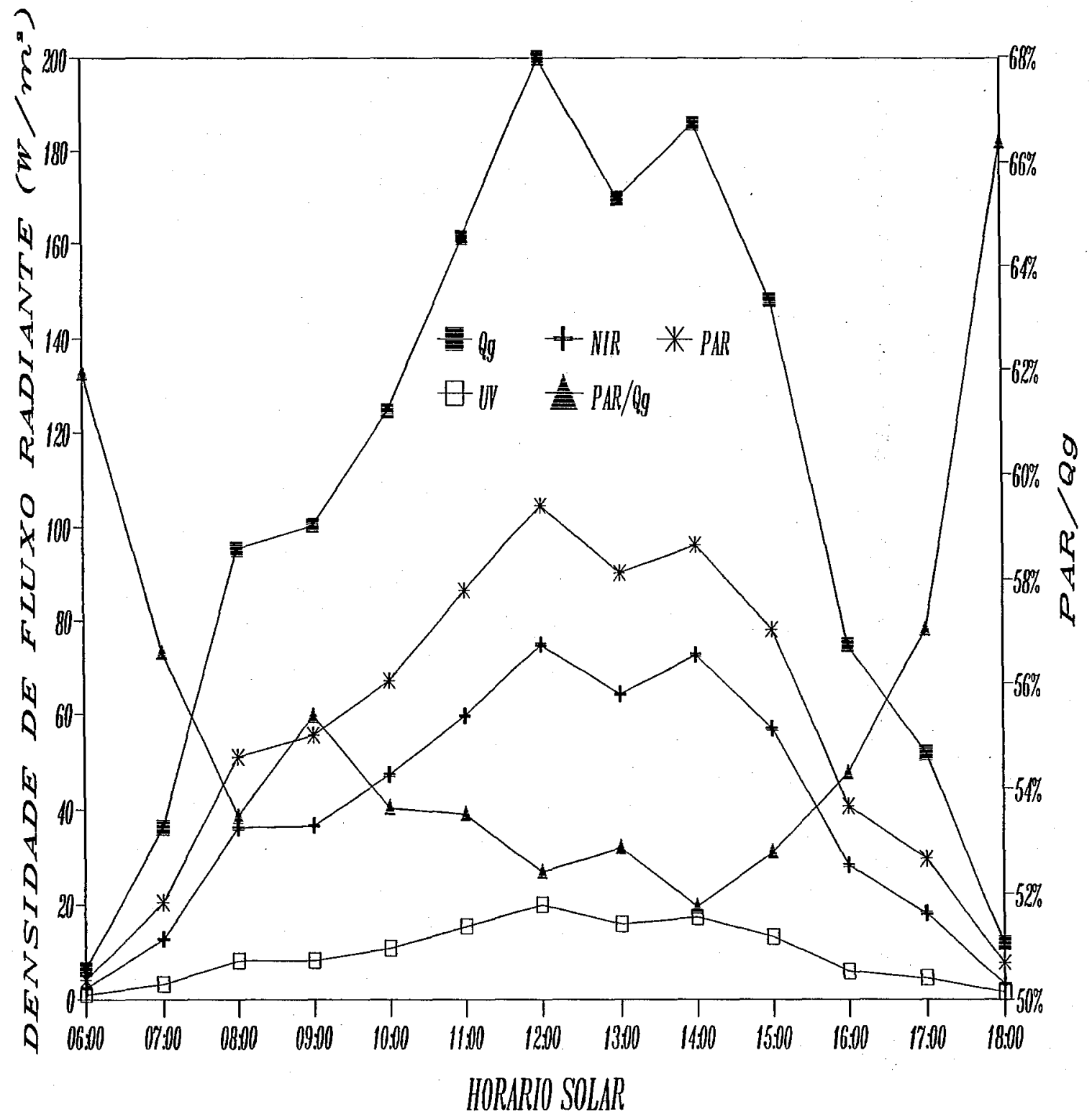

Figura 13: Evolução horária da distribuição espectral da radiação solar e da fração fotossinteticamente ativa para dia com céu totalmente nublado (média de 7 dias). 
Nota-se na Figura 14, página 38, uma pequena dispersão entre 0 e $10^{\circ}$, isto devido a um maior caminho ótico, proporcionando uma quantidade maior de vapor d'água na atmosfera atravessada pela radiação no período da manhã e da tarde. Na Figura 15, página 39, também nota-se uma pequena dispersão, mas entre 30 e $40^{\circ}$, isto está ligado possivelmente ao tipo de nuvem predominante neste horário.

Todavia não foi possível avaliar os dias com céu parcialmente nublados, visto à grande dificuldade encontrada na integração horária destes dados e também à grande combinação dos tipos de nuvem, hora de passagem pelo céu naquela latitude, enfim, muitos outros fatores dificultam de maneira direta e indireta a estimativa da PAR nestas condições. 


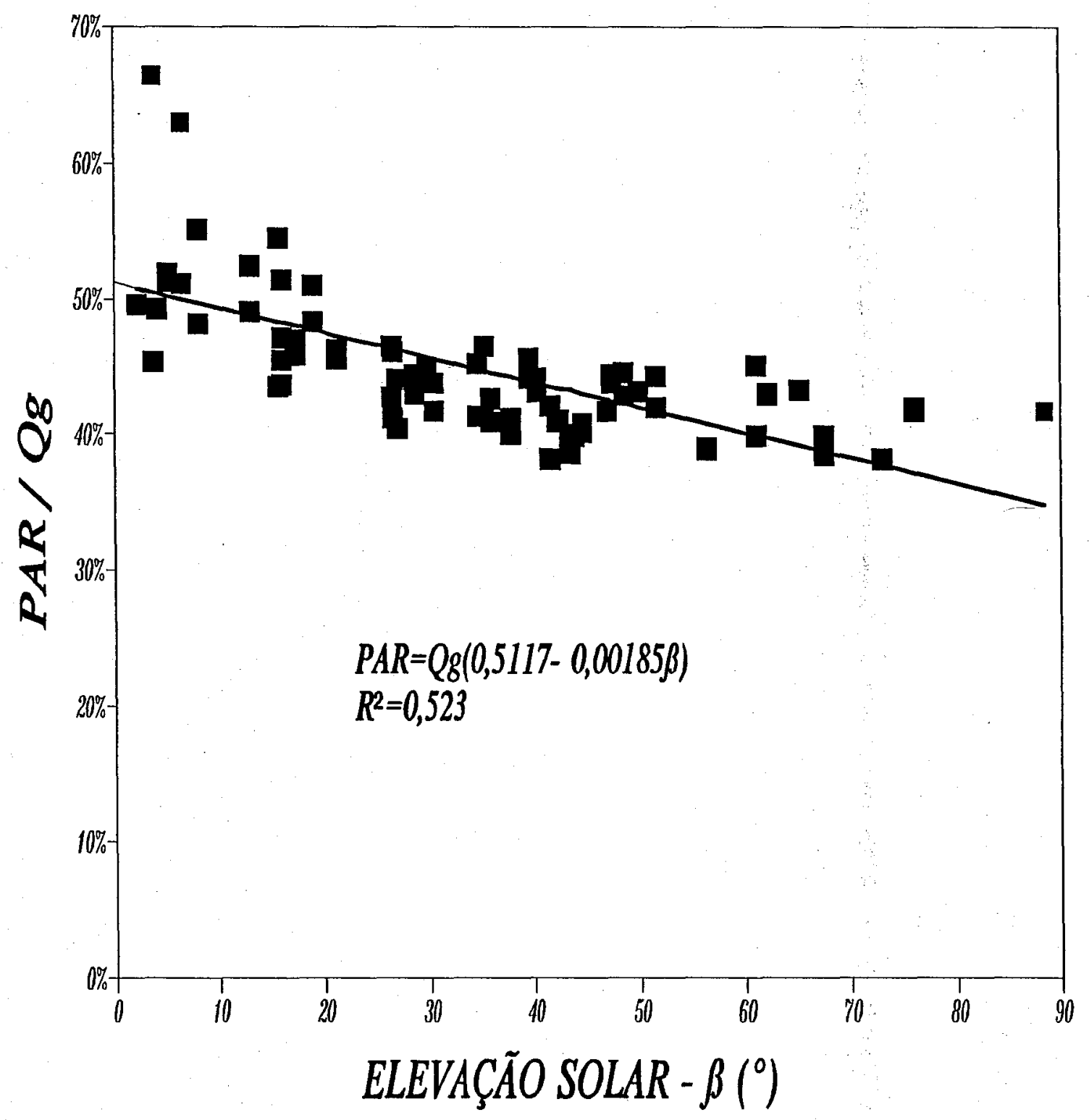

Figura 14: Relação entre PAR e Qg em função da elevação solar para um dia completamente limpo, em Piracicaba-sP. 


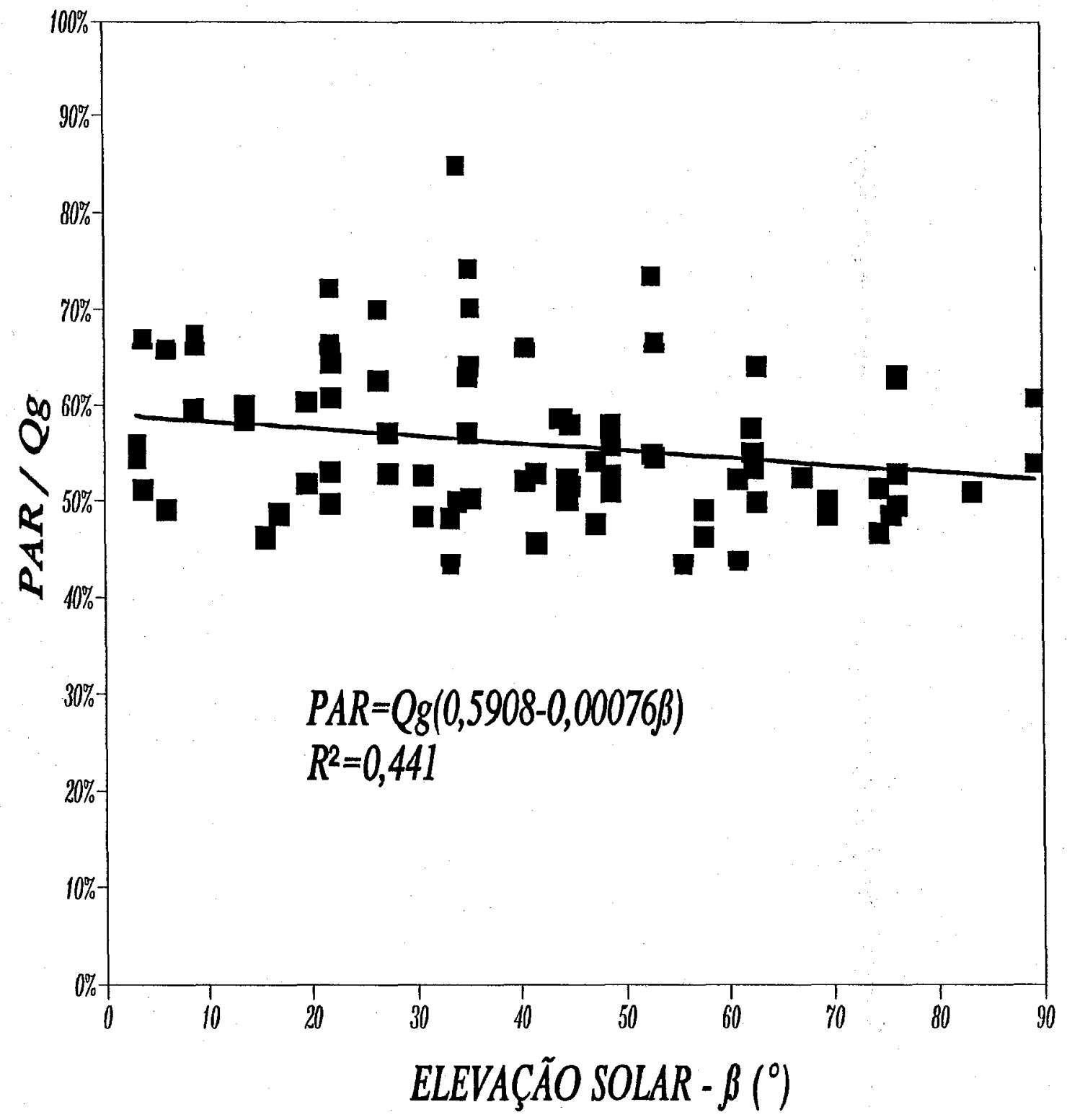

Figura 15: Relação entre PAR e Qg em função da elevação solar para um dia completamente nublado, em Piracicaba-sP. 


\section{CONCLUSÕES}

Mediante os dados obtidos nos diferentes métodos de estimativas da radiação fotossinteticamente ativa (PAR) e radiação infravermelho próximo (NIR) possibilitou-se tirar as seguintes conclusões:

5.1. A densidade de fótons fotossintéticos em $\mathrm{E} / \mathrm{m}^{2}$.dia, nas condiçōes atmosféricas de Piracicaba-SP, pode ser estimada por $P A R=1,9509$, sendo a radiação global dada em $\mathrm{MJ} / \mathrm{m}^{2}$. dia.

5.2. Nas mesmas condições, a PAR pode ser estimada em $\mathrm{MJ} / \mathrm{m}^{2}$.dia, multiplicando-se por 0,44 a radiação global na mesma unidade, ou seja $P A R=0,44 \mathrm{Qg}$.

5.3. Pode-se estimar a $\mathrm{PAR}$ em $\mathrm{MJ} / \mathrm{m}^{2}$.dia, utilizando-se as seguintes relaçōes: $P A R=0,41709$, para dias em que $n / N \leq 0,1 ; P A R=0,429 Q g$ quando $0,1<n / N<0,9$ e PAR=0,496Qg quando $n / N \geq 0,9$.

5.4. A contribuição da PAR para a radiação global é de 0,399 quando $(n / N)=1$ e de 0,501 quando $(n / N)=0$.

5.5. A radiação fotossinteticamente ativa determinada pelo método direto é cerca de $10 \%$ menor que a radiação fotossinteticamente ativa determinada pelo método indireto.

5.6. Na ausência da radiação global, pode-se estimar a PAR, em $\mathrm{E} / \mathrm{m}^{2} . \mathrm{dia}$, adotando-se a seguinte expressão $\operatorname{PAR}=Q \circ[0,498+0,816(\mathrm{n} / \mathrm{N})]$, similarmente, a estimativa da radiação infravermelho próximo, em $\mathrm{MJ} / \mathrm{m}^{2}$.dia, é dada por $\operatorname{NIR}=Q \circ[0,091+0,239(\mathrm{n} / \mathrm{N})]$, onde Qo é dado em $\mathrm{MJ} / \mathrm{m}^{2} \cdot \mathrm{dia}$.

5.7. Em estudos envolvendo variações horárias 
da radiação fotossinteticamente ativa ao longo do dia, em Piracicaba, a expressão PAR $=Q 9[0,5117-0,00185(B)]$ para dias sem nuvens e a expressão $P A R=Q g[0,5908-0,00076(B)]$ para dias nublados podem ser usadas. A densidade de fluxo da radiação fotossinteticamente ativa e da radiação global são dadas em $\mathrm{W} / \mathrm{m}^{2}$, e a elevação solar em graus.

5.8. A fração ultravioleta varia entre 8 a $12 \%$ dentro da radiação global, nas condições atmosféricas estudadas em Piracicaba-SP. 


\section{REFERÊNCIAS BIBLIOGRÁFICAS}

ALMEIDA, R.; SALATI, E.; VILLA NOVA, N. A. Distribuição espectral e coeficientes de transmissão da radiação solar para condições de céu limpo em Manaus. Acta Amazonica, Manaus, $9(2): 279-85,1979$.

ANUÁRIO ASTRONÔMICO, 1993, São Paulo, 23-9, 1992.

ASSIS, F.N. \& MENDEZ, M.E.G. Relação entre radiação fotossinteticamente ativa e radiação global. Pesquisa Agropecuária Brasileira, Brasillia, $24(7): 797-800,1989$.

BARKER, H. W. Solar radiative transfer through clouds possessing isotropic variable extintion coefficient. Quarterly Journal of the Royal Meteorological society, Bracknell, 118:1145-62, 1992 .

BLUM, H. \& SCHWANK, $O$. The stability of the calibration factors of sensor for photosynthetically active radiation used in wet conditions. Agricultural and Forest Meteorology, Amsterdam, 34:77-82, 1985.

BRASIL. Ministério da Indústria e do Comércio. Secretaria de Tecnologia Industrial. Manual de Energia Solar. Brasilia, 1978. 54p.

BRITTON, C.M. \& DODD, J.D. Relationships of photosynthetically active radiation and shortwave irradiance. Agricultural Meteorology, Amsterdam, 17:1-7, 1976.

COULSON, K. L. Solar and terrestrial radiation. New York, Academic Press, 1975. 322p.

GATES, D. M. Biophysical ecology. New York, Springer-Verlag, 1980. 611p. 
GOODY, R. M. Atmospheric radiation, I theoretical basis. Oxiford, oxford University Press, 1964, 436p.

GUEYMARD, C. An atmospheric transmittance model for the calculation of the clear sky beam, diffuse and global photosynthetically active radiation. Agricultural and Forest Meteorology, Amsterdam, 45:215-29, 1989.

HANSEN, V. Spectral distribution of solar radiation on clear days: a comparason between measurement and model estimates. Journal of Climate and Applied Meteorology, Boston, $23: 772-80,1984$.

HATFIELD, J. L. \& CARLSON, R. E. Photosynthetically active radiation, $\mathrm{CO} 2$ uptake, and stomatal diffusive resistance profiles whithin soybean canopies. Agronomy Journal, Madison, 70:592-6, 1978 .

HIPPS, L. E. Assessing the interception of photosynthetically active radiation in winter wheat. Agricultural Meteorology, Amsterdam, 28:253-9, 1983.

HOWELL, T.A.; MEEK, D.W.; HATFIELD, J.L. Relationship of photosynthetically active radiation to shortwave in the San Joaquin Valley. Agricultural Meteorology, Amsterdam, $70: 157-75,1983$.

HOWELL, T.A.; MEEK, D.W.; HATFIELD, J.L.; IDSO, S.B.; REJINATO, R.J. A generalised relationship between photosynthetically active radiation and solar radiation. Agronomy Journal, Madison, 76:939-45, 1984 .

JUSTUS, C. G.; PARIS, M. V. A model for solar spectral irradiance and radiance at the bottom and top of a cloudless atmosphere. Journal of climate and Applied Meteorology, Boston, 23(3):193-205, 1985 .

KARALIS, J. D. Characteristics of direct photosynthetically active radiation. Agricultural and Forest Meteorology, Amsterdam, 48:225-34, 1989.

KUUSK, A. Absorption profiles of shortwave radiation in a vegetation canopy. Agricultural and Forest Meteorology, Amsterdam, 62 :191-204, 1992 . 
LAUE, E.G. \& DRUMMOND, A.J. Solar constant, first direct measurements. Science, New York, 161:888-91, 1968.

LI-COR. LI-190SB quantum sensor instruction manual. Lincoln, 1980. 46p. (Publication, 8004-0.)

MACHADO, E. C. Um modelo matemático-fisiológico para simular - acúmulo de matéria seca na cultura de cana-de-açúcar (Saccharum sp). Campinas, 1981. 115p. (Mestrado em Biologia/UNICAMP) .

MACHADO, E. C.; PEREIRA, A. R.; CAMARGO, M. B. P.; FAHL, J. I. Relações radiométricas de uma cultura de cana-deaçúcar. Bragantia, Campinas, 44(1):229-38, 1985.

MCCREE, K. J. The test action spectrum absorptance and quantum yield of photosynthesis in crop plants. Agricultural Meteorology, Amsterdam, 9:191-216, 1971/72. MCCREE, K. J. Test of current definitions of photosynthetically active radiation against leaf photosynthesis data. Agricultural Meteorology, Amsterdam, 10: 443-53, 1972 .

MCCREE, K. J. Daily photosynthesis totals calculated from solar radiation histograms. Agricultural and Forest Meteorology, Amsterdam, 33:239-48, 1984 .

MITCHELL, P. L. \& WOODWARD, F. I. Instrument for measuring temperature, photosynthetically active radiation and daylength, and its use in the measurement of daylength and temperature in coppice. Journal of Applied of Ecology, oxford, 24:239-49, 1987.

MONTEITH, J. L. An empirical method for estimating long-wave radiation exchanges in the British Isles. Quarterly Journal of the Royal Meteorological society, Bracknell, $87: 171-79,1962$.

MONTEITH, J. L. \& UNSWORTH, M.H. Enviromental phisycs. London, Edward Arnold, 1990. 291p.

MOTA, F. S. Meteorologia agrícola. São Paulo, Nobel, 1986. $376 \mathrm{p}$. 
NEWMAN, S. M. Low-cost sensor integrators for measuring the transmissivity of complex canopies to photosynthetically active radiation. Agricultural and Forest Meteorology. Amsterdam, 35:243-54, 1985.

NOBEL, P. S. Physicochemical and environmental plant physiology. San Diego, Academic Press, 1991. 635p.

OMETTO, J. C. Estudo das relações entre: radiação solar global, radiação líquida e insolação. Piracicaba, 1968, (Doutorado - Escola superior de Agricultura "Luiz de Queiroz"/USP.

OMETTO, J. C.; CERVELLINI, A.; SALATI, E. Estudo da radiação solar em piracicaba. Piracicaba, ESALQ/Departamento de Física e Meteorologia, 1967. 19p.

OMETTO, J. C.; VILLA NOVA, N. A.; TANAKA, M. M. Estudo da transmissividade média da atmosfera para a radiação solar em função do tipo de cobertura. Piracicaba, ESALQ/Departamento de Física e Meteorologia, 1971. 40p. PEREIRA, A. R. \& ARRUDA, H. V. Ajuste prático de curvas na pesquisa biológica. Campinas, Fundação Cargill, 1987. $50 \mathrm{p}$.

PEREIRA, A. R.; MACHADO, E. C.; CAMARGO, M. B. P. Solar radiation regime in three cassava (Manihot esculenta Crantz) canopies. Agricultural Meteorology, Amsterdam, $26: 1-10,1982$.

ROBINSON, N. Solar radiation. New York, Elsevier, 1966. $347 \mathrm{p}$.

SELLERS, W. D. Physical climatology - Chicago, The University of Chicago Press, 1967. 272p.

SMOLANDER, H. \& LAPPI, J. Integration of a nonlinear function in a changing enviroment: estimating photosynthesis using meanand variance of radiation. Agricultural and Forest Meteorology, Amsterdam, 34:83-91, 1985.

STANHILL, G. \& FUCHS, M. The relative flux density of photosynthetically active radiation. Journal of Applied Ecology, oxford, 14:317-22, 1977 . 
STIGTER, C. J. \& MUSABILHA, M. M. The conservative ratio of photosynthetically active to radiation in the tropics. Journal of Applied of Ecology, Oxford, 19:853-8, 1982. SURAQUI, S. Spectral measurements of global radiation in Israel. Israel Journal of Agricultural Research, Jerusalem, 22 (2):119-23, 1972.

SZEICZ, G. Solar radiation for plant growth. Journal of Applied Ecology, Oxford, 11:617-36, 1974 .

TING, K. C. \& GIACOMELLI, G. A. Solar photosynthetically active radiation transmission through greenhouse glazings. Energy in Agriculture, Amsterdam, 6:121-32, 1987.

VIANELLO, R. L. \& ALVES, A. R. Meteorologia básica e aplicações, Viçosa, Imprensa Universitária, 1991. 449p.

VILlA NOVA, N. A.; GÓES RIBEIRO, M. N.; NOBRE, C. A.; SALATI, E. Radiação solar em manaus. Acta Amazonica, Manaus, 8(3): 417-21, 1978.

VILLA NOVA, N. A.; SALATI, E.; SANTOS, J. M. ; RIBEIRO, M. N. G. Coeficientes de transmissão de radiação solar em manaus em junho. Acta Amazonica, Manaus, 6(3):319-22, 1976.

VILLA NOVA, N. A.; GODOY, C. R. M.; FERRAZ, E. S. B.; OMETTO, J. C.; DECICO, A.; PEDRO JR., M. J. Radiação solar disponível a diferentes exposições, na ausência da atmosfera (radiação direta). Piracicaba, ESALQ/Departamento de Física e Meteorologia, 1970. 21p. WEISS, A. \& NORMAN, J. M. Partitioning solar radiation into direct and diffuse, visible and near-infrared components. Agricultural and Forest Meteorology, Amsterdam, 34:205-13, 1985 . 
APÊNDICE 1 
INTEGRA DOS DADOS DIÁRIOS UTILIZADOS (1993): Razão de insolação ( $\mathrm{n} / \mathrm{N})$, Radiação no Topo da atmosfera (QO), Radiação Global (Qg), Radiação Infravermelho próximo (NIR) e Radiação Fotossinteticamente ativa (PAR).

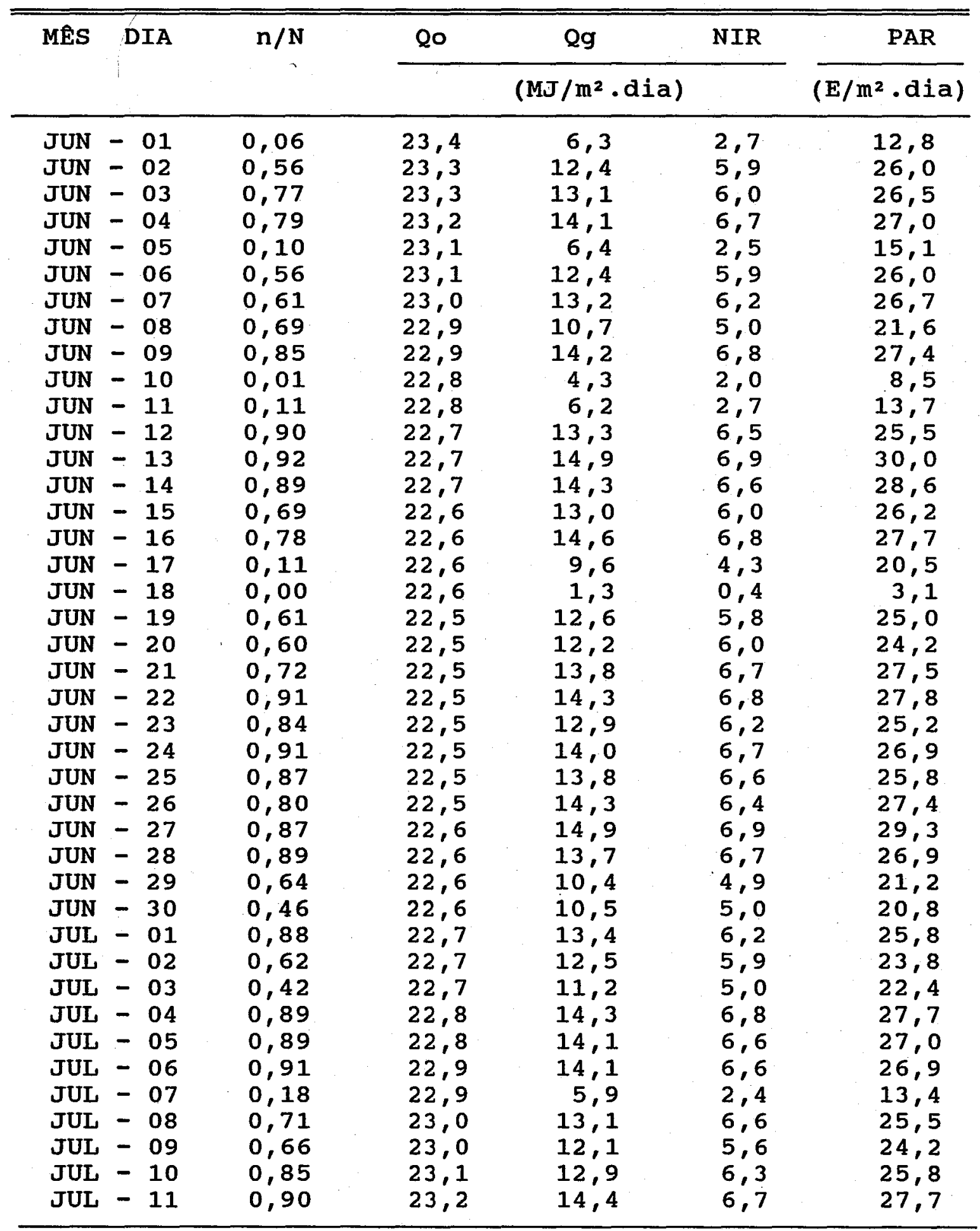


. . continuação. . .

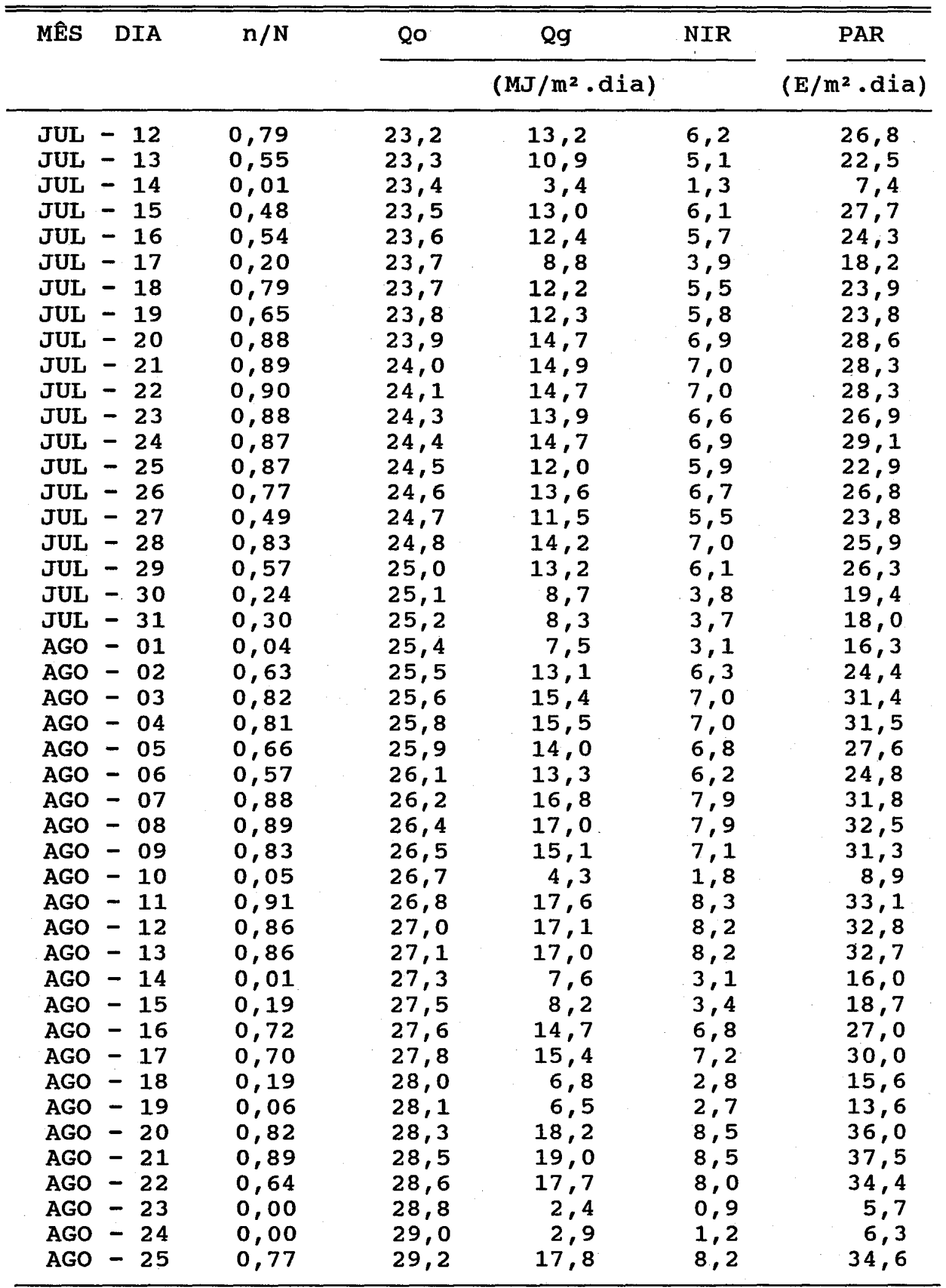


... continuação...

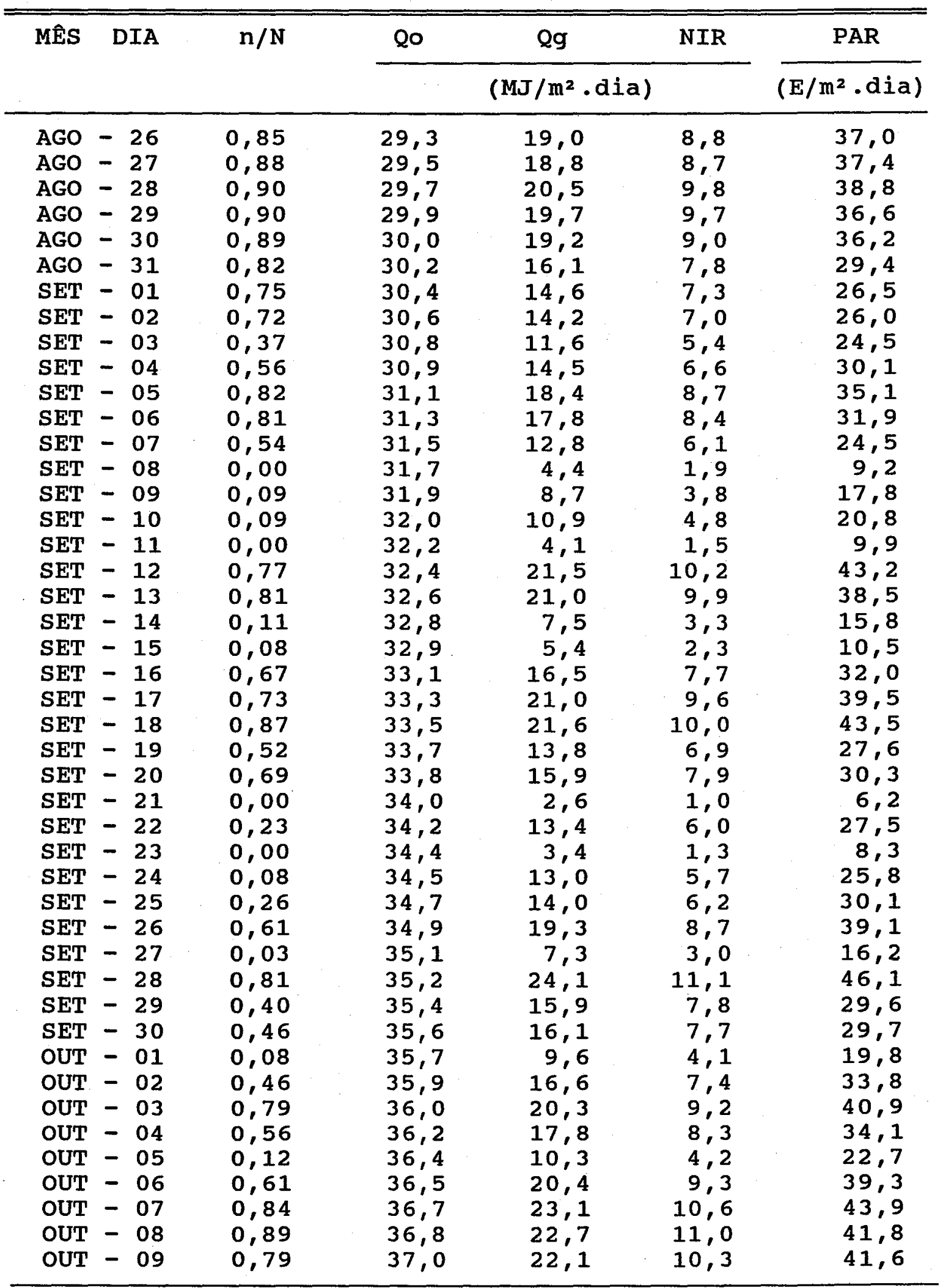


... continuação...

\begin{tabular}{|c|c|c|c|c|c|c|}
\hline \multirow[t]{2}{*}{ MES } & \multirow[t]{2}{*}{ DIA } & \multirow[t]{2}{*}{$\mathrm{n} / \mathrm{N}$} & QO & Qg & NIR & \multirow{2}{*}{$\frac{\mathrm{PAR}}{\left(\mathrm{E} / \mathrm{m}^{2} \cdot \mathrm{dia}\right)}$} \\
\hline & & & \multicolumn{3}{|c|}{$\left(\mathrm{MJ} / \mathrm{m}^{2} \cdot \mathrm{dia}\right)$} & \\
\hline OUT & -10 & 0,79 & 37,1 & 21,3 & 10,1 & 41,4 \\
\hline OUT & -11 & 0,86 & 37,3 & 22,3 & 11,2 & 39,7 \\
\hline OUT & -12 & 0,82 & 37,4 & 22,1 & 10,7 & 42,1 \\
\hline OUT & -13 & 0,81 & 37,6 & 20,6 & 10,2 & 36,9 \\
\hline OUT & -14 & 0,72 & 37,7 & 15,1 & 7,3 & 27,5 \\
\hline OUT & -15 & 0,24 & 37,9 & 6,4 & 2,7 & 14,4 \\
\hline OUT & -16 & 0,00 & 38,0 & 14,5 & 5,8 & 32,1 \\
\hline OUT & -17 & 0,23 & 38,2 & 18,2 & 8,0 & 37,3 \\
\hline OUT & -18 & 0,48 & 38,3 & 23,1 & 11,0 & 46,5 \\
\hline OUT & -19 & 0,72 & 38,4 & 23,9 & 11,1 & 46,0 \\
\hline OUT & -20 & 0,74 & 38,6 & 23,7 & 10,8 & 45,7 \\
\hline OUT & -21 & 0,68 & 38,7 & 19,6 & 9,5 & 37,9 \\
\hline OUT & -22 & 0,71 & 38,8 & 10,3 & 5,4 & 18,5 \\
\hline OUT & -23 & 0,08 & 39,0 & 9,2 & 4,0 & 18,9 \\
\hline OUT & -24 & 0,06 & 39,1 & 17,0 & 6,8 & 35,3 \\
\hline OUT & -25 & 0,43 & 39,2 & 7,6 & 3,3 & 16,6 \\
\hline OUT & -26 & 0,04 & 39,3 & 21,8 & 9,1 & 45,2 \\
\hline OUT & -27 & 0,56 & 39,4 & 21,6 & 10,0 & 41,1 \\
\hline OUT & -28 & 0,57 & 39,6 & 26,9 & 12,7 & 53,0 \\
\hline OUT & -29 & 0,89 & 39,7 & 22,5 & 10,8 & 44,1 \\
\hline OUT & -30 & 0,83 & 39,8 & 23,3 & 10,6 & 45,8 \\
\hline NOV & -01 & 0,77 & 40,0 & 25,4 & 11,3 & 50,4 \\
\hline NOV & -02 & 0,16 & 40,1 & 13,8 & 6,0 & 28,3 \\
\hline NOV & -03 & 0,89 & 40,2 & 26,0 & 12,8 & 50,8 \\
\hline NOV & -04 & 0,88 & 40,3 & 31,4 & 15,5 & 57,6 \\
\hline NOV & -05 & 0,71 & 40,4 & 21,8 & 10,4 & 40,0 \\
\hline NOV & -06 & 0,23 & 40,5 & 15,5 & 7,0 & 33,3 \\
\hline NOV & -07 & 0,05 & 40,6 & 6,2 & 2,6 & 12,8 \\
\hline NOV & -08 & 0,27 & 40,7 & 15,3 & 7,1 & 32,7 \\
\hline NOV & -09 & 0,85 & 40,8 & 27,1 & 12,9 & 50,0 \\
\hline NOV & -10 & 0,81 & 40,9 & 22,6 & 11,2 & 40,2 \\
\hline NOV & -11 & 0,72 & 41,0 & 23,1 & 11,4 & 45,2 \\
\hline NOV & -12 & 0,88 & 41,1 & 26,7 & 12,7 & 50,2 \\
\hline NOV & -13 & 0,79 & 41,2 & 23,7 & 11,4 & 44,2 \\
\hline NOV & -14 & 0,77 & 41,2 & 21,5 & 10,3 & 38,2 \\
\hline NOV & -15 & 0,76 & 41,3 & 25,3 & 13,0 & 44,7 \\
\hline NOV & -16 & 0,64 & 41,4 & 21,6 & 10,0 & 40,9 \\
\hline NOV & -17 & 0,48 & 41,5 & 23,2 & 10,1 & 49,6 \\
\hline NOV & -18 & 0,43 & 41,5 & 16,6 & 7,6 & 35,2 \\
\hline NOV & -19 & 0,59 & 41,6 & 22,7 & 10,8 & 44,1 \\
\hline NOV & -20 & 0,91 & 41,7 & 28,4 & 13,6 & 55,6 \\
\hline NOV & -21 & 0,87 & 41,7 & 28,7 & 14,5 & 55,9 \\
\hline NOV & -22 & 0,58 & 41,8 & 20,8 & 10,0 & 37,2 \\
\hline NOV & -24 & 0,52 & 41,9 & 20,8 & 9,6 & 43,0 \\
\hline NOV & -25 & 0,24 & 42,0 & 16,6 & 7,5 & 34,7 \\
\hline
\end{tabular}


... continuação...

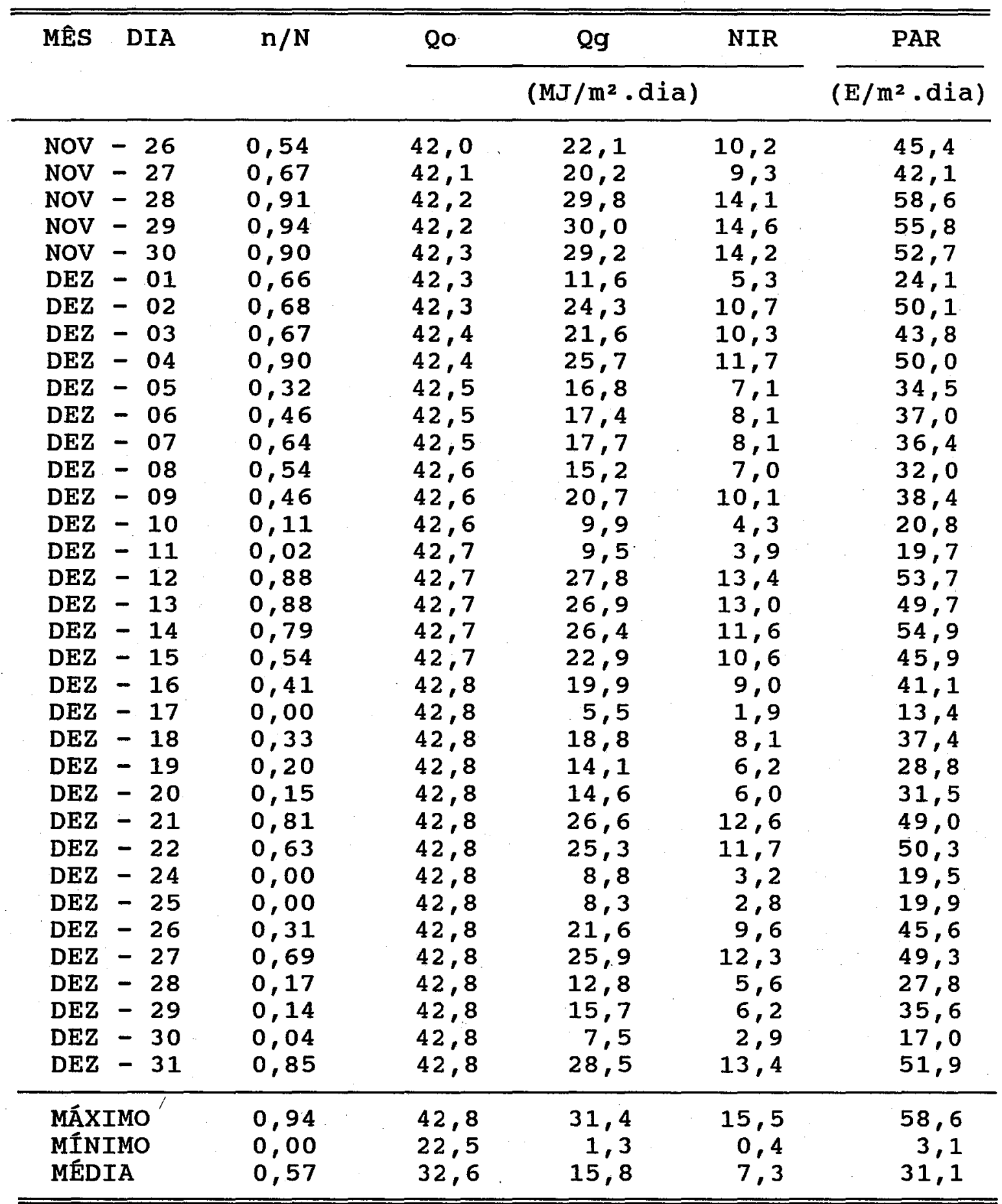


APÊNDICE 2 
ÍNTEGRA DOS DADOS HORÁRIOS UTILIZADOS: Radiação global(Qg), radiação infravermelho próximo (NIR) e radiação fotossinteticamente ativa (PAR).

$\mathrm{DIA}: 18 / 06, \mathrm{n} / \mathrm{N}=0,00 \quad \mathrm{DIA}: 22 / 06, \mathrm{n} / \mathrm{N}=0,91$

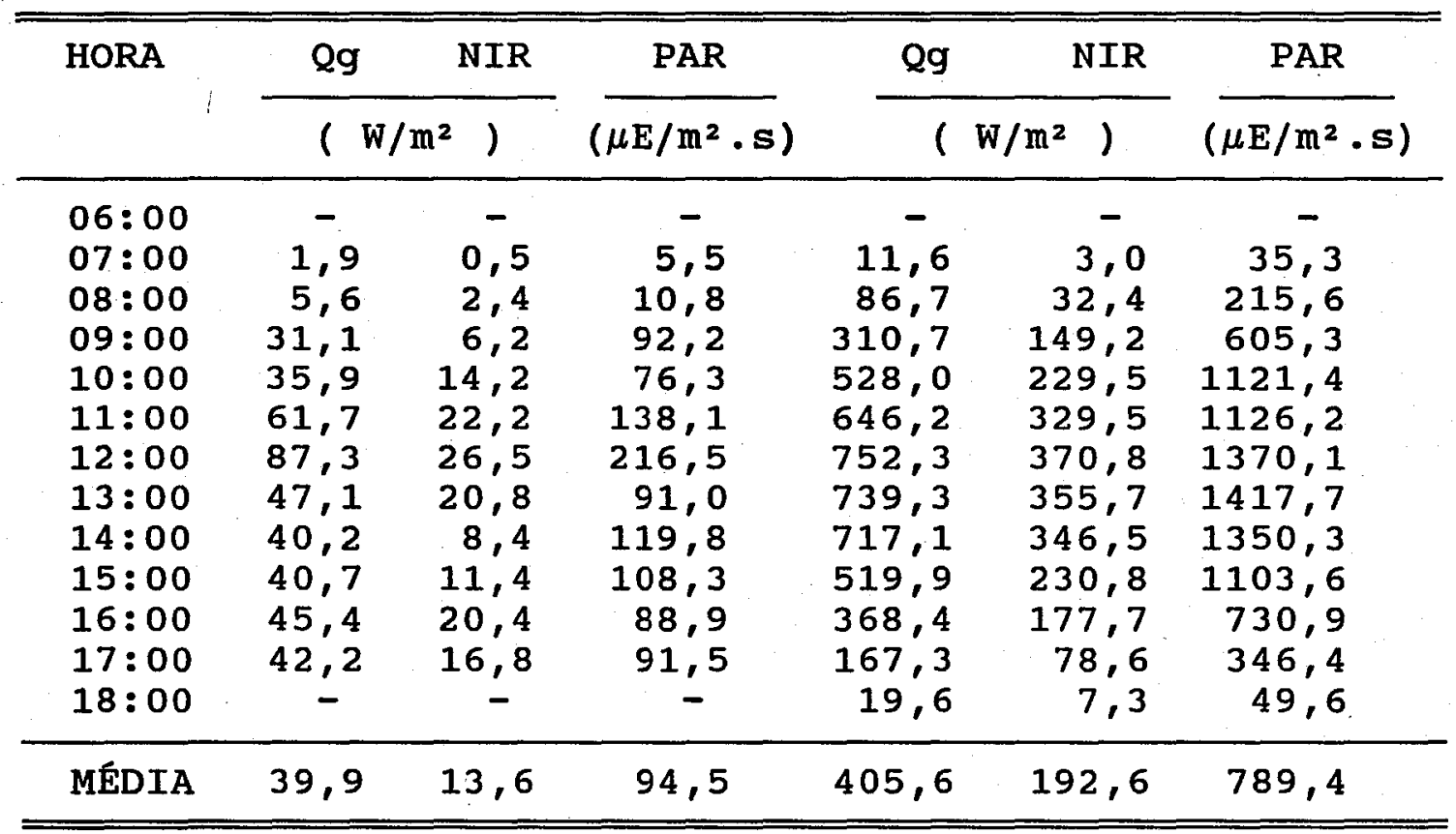

DIA: $06 / 07, n / N=0,91$

DIA: $22 / 07, \mathrm{n} / \mathrm{N}=0,90$

\begin{tabular}{|c|c|c|c|c|c|c|}
\hline \multirow[t]{2}{*}{ HORA } & Qg & NIR & \multirow{2}{*}{$\frac{\mathrm{PAR}}{\left(\mu \mathrm{E} / \mathrm{m}^{2} \cdot \mathrm{s}\right)}$} & \multirow{2}{*}{$\frac{\mathrm{Qg}}{(}$} & NIR & \multirow{2}{*}{$\frac{\mathrm{PAR}}{\left.\mu \mathrm{E} / \mathrm{m}^{2} \cdot \mathrm{s}\right)}$} \\
\hline & \multicolumn{2}{|c|}{$\left(\mathrm{W} / \mathrm{m}^{2}\right)$} & & & $\left.W / m^{2}\right)$ & \\
\hline $\begin{array}{l}06: 00 \\
07: 00 \\
08: 00 \\
09: 00 \\
10: 00 \\
11: 00 \\
12: 00 \\
13: 00 \\
14: 00 \\
15: 00 \\
16: 00 \\
17: 00 \\
18: 00\end{array}$ & $\begin{array}{r}- \\
25,9 \\
229,5 \\
444,2 \\
600,7 \\
726,9 \\
739,4 \\
720,7 \\
608,5 \\
410,3 \\
224,1 \\
43,8 \\
-\end{array}$ & $\begin{array}{r}- \\
10,9 \\
104,5 \\
206,4 \\
281,2 \\
337,9 \\
346,6 \\
336,5 \\
291,4 \\
206,6 \\
107,8 \\
18,3 \\
-\end{array}$ & $\begin{array}{r}- \\
58,5 \\
476,3 \\
892,4 \\
1167,2 \\
1362,8 \\
1372,8 \\
1344,8 \\
1137,3 \\
754,9 \\
445,9 \\
98,5 \\
-\end{array}$ & $\begin{array}{r}- \\
19,4 \\
169,3 \\
386,9 \\
586,4 \\
734,8 \\
783,2 \\
681,7 \\
669,9 \\
506,3 \\
290,7 \\
91,9 \\
-\end{array}$ & $\begin{array}{r}- \\
8,0 \\
76,0 \\
185,7 \\
281,8 \\
358,5 \\
365,4 \\
330,4 \\
328,2 \\
235,0 \\
133,5 \\
37,3 \\
-\end{array}$ & $\begin{array}{r}- \\
45,5 \\
363,7 \\
758,8 \\
1101,4 \\
1345,2 \\
1491,7 \\
1268,2 \\
1224,1 \\
1025,3 \\
608,3 \\
217,6 \\
-\end{array}$ \\
\hline MÉDIA & 434,0 & 204,4 & 828,3 & 447,3 & 212,7 & 859,1 \\
\hline
\end{tabular}


...continuação...

DIA: $04 / 08, n / N=0,81$

$\mathrm{DIA}: 23 / 08, \mathrm{n} / \mathrm{N}=0,00$

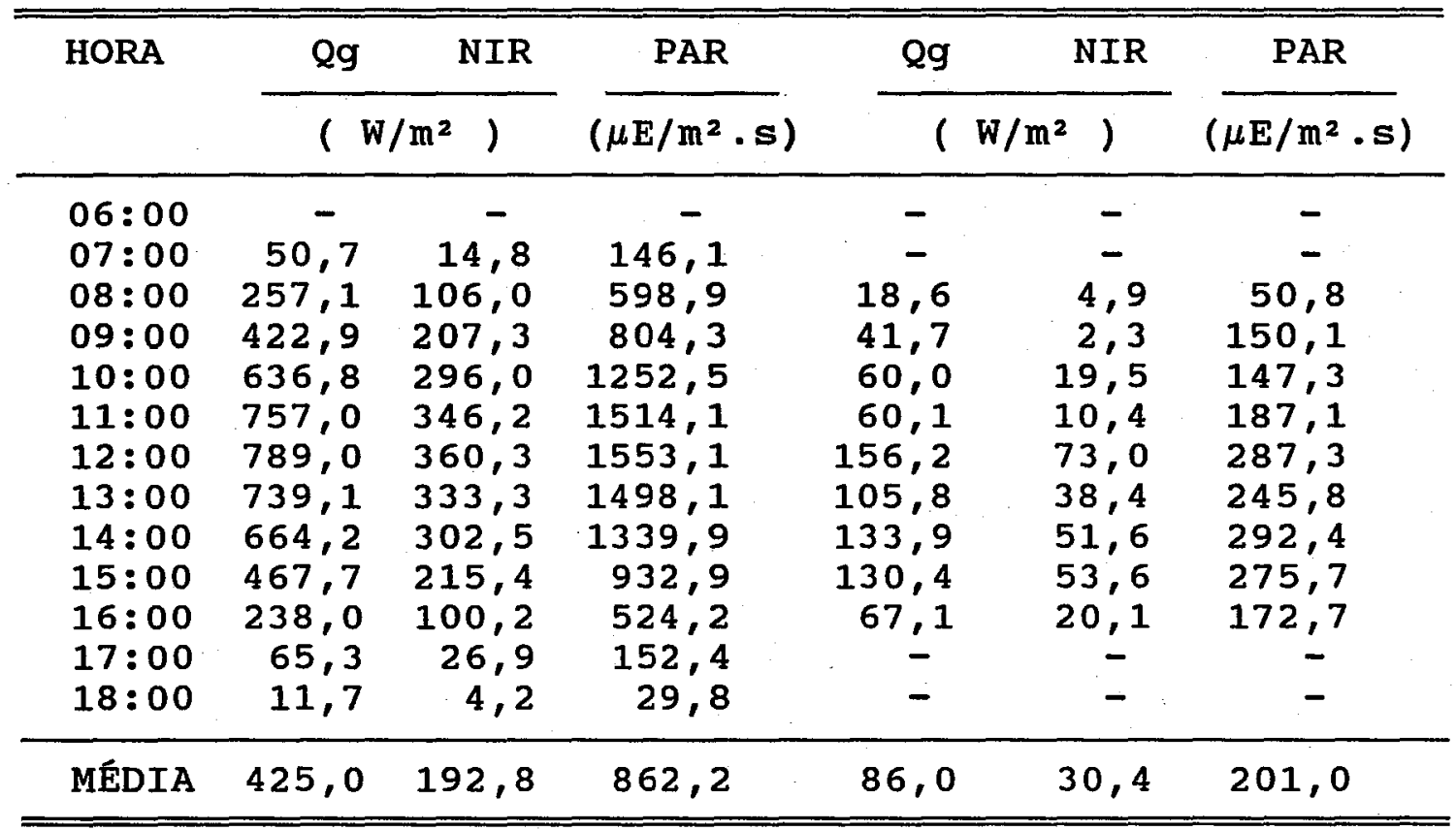

DIA: $18 / 09, n / N=0,90$

DIA: $23 / 09, n / N=0,00$

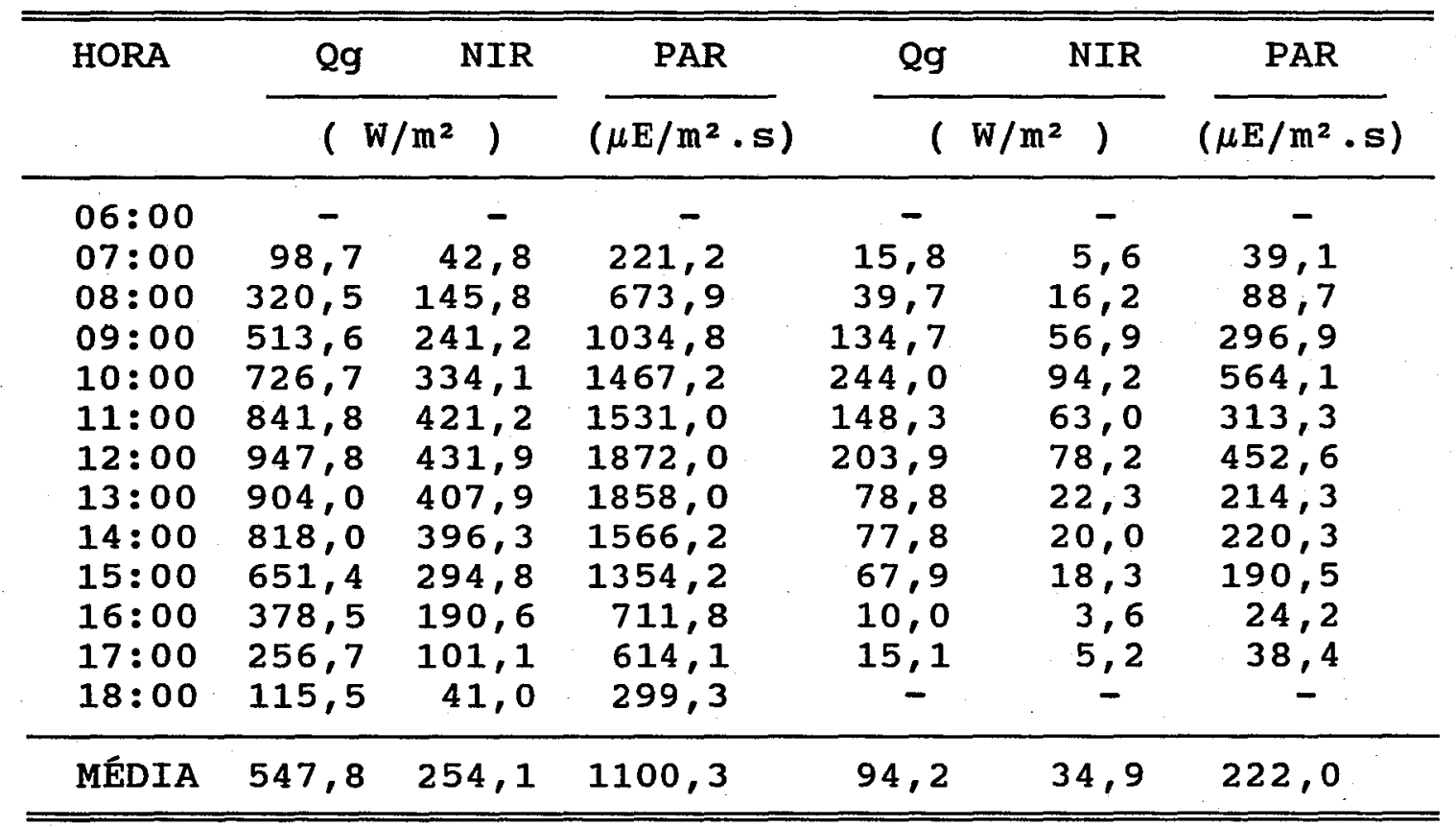


...continuação...

DIA : $08 / 10, n / N=0,90$

DIA: $15 / 10, n / N=0,00$

\begin{tabular}{|c|c|c|c|c|c|c|}
\hline \multirow[t]{2}{*}{ HORA } & Qg & NIR & PAR & Qg & NIR & \multirow{2}{*}{$\frac{\mathrm{PAR}}{\left(\mu \mathrm{E} / \mathrm{m}^{2} \cdot \mathrm{s}\right)}$} \\
\hline & \multicolumn{2}{|c|}{$\left(\mathrm{w} / \mathrm{m}^{2}\right)$} & $\left(\mu \mathrm{E} / \mathrm{m}^{2} \cdot \mathrm{s}\right)$ & ( & $\left.W / m^{2} \quad\right)$ & \\
\hline $\begin{array}{l}06: 00 \\
07: 00 \\
08: 00 \\
09: 00 \\
10: 00 \\
11: 00 \\
12: 00 \\
13: 00 \\
14: 00 \\
15: 00 \\
16: 00 \\
17: 00 \\
18: 00\end{array}$ & $\begin{array}{r}- \\
91,2 \\
264,3 \\
492,7 \\
710,1 \\
849,8 \\
913,1 \\
898,5 \\
837,1 \\
667,9 \\
499,0 \\
251,4 \\
66,9\end{array}$ & $\begin{array}{r}- \\
40,4 \\
122,9 \\
246,9 \\
359,7 \\
404,2 \\
449,8 \\
444,9 \\
413,8 \\
332,1 \\
225,9 \\
98,7 \\
27,8\end{array}$ & $\begin{array}{r}- \\
196,1 \\
535,6 \\
900,5 \\
1258,4 \\
1545,3 \\
1591,4 \\
1577,7 \\
1490,4 \\
1176,9 \\
1024,4 \\
589,7 \\
151,6\end{array}$ & $\begin{array}{r}13,1 \\
76,4 \\
78,1 \\
119,7 \\
168,4 \\
231,2 \\
260,9 \\
418,3 \\
200,3 \\
116,8 \\
112,7 \\
58,6 \\
3,2\end{array}$ & $\begin{array}{r}5,2 \\
34,4 \\
34,7 \\
50,4 \\
73,0 \\
95,1 \\
109,1 \\
178,7 \\
91,6 \\
48,6 \\
46,0 \\
26,2 \\
1,2\end{array}$ & $\begin{array}{r}30,1 \\
157,8 \\
160,2 \\
254,0 \\
351,1 \\
490,7 \\
536,7 \\
859,4 \\
392,5 \\
259,0 \\
251,4 \\
120,5 \\
7,5\end{array}$ \\
\hline MEDIA & 545,2 & 263,9 & 1003,2 & 142,9 & 61,1 & 297,8 \\
\hline
\end{tabular}

DIA: $07 / 11, n / N=0,04$

DIA: $28 / 11, n / N=0,91$

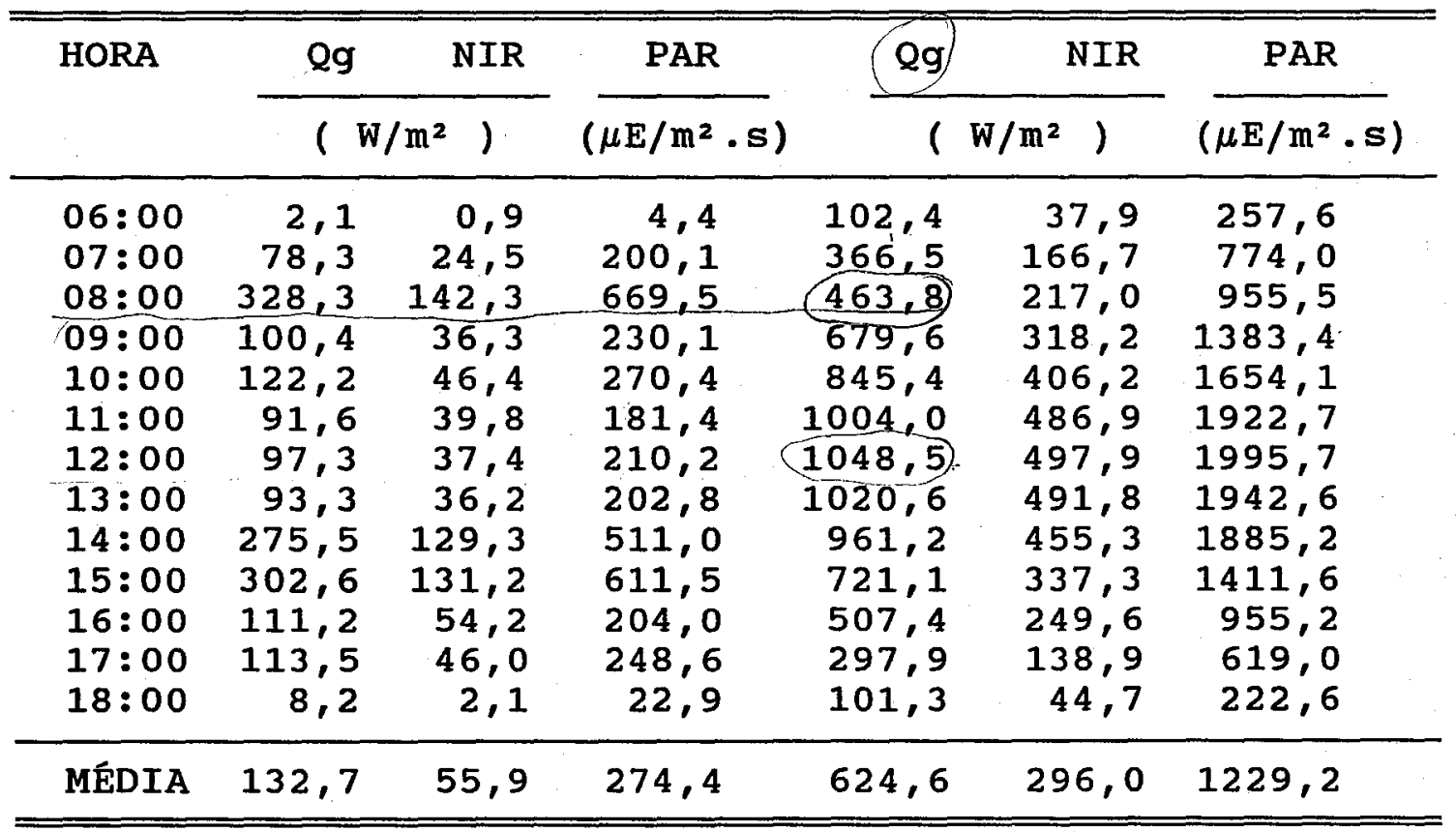


... continuação...

\begin{tabular}{|c|c|c|c|c|c|c|}
\hline \multirow[t]{2}{*}{ HORA } & Qg & NIR & PAR & Qg & NIR & \multirow{2}{*}{$\frac{\text { PAR }}{\left(\mu \mathrm{E} / \mathrm{m}^{2} \cdot \mathrm{s}\right)}$} \\
\hline & \multicolumn{2}{|c|}{$\left(w / m^{2}\right.$} & $\left(\mu \mathrm{E} / \mathrm{m}^{2} \cdot \mathrm{s}\right)$ & ( & $\mathrm{W} / \mathrm{m}^{2} \quad$ ) & \\
\hline $\begin{array}{l}06: 00 \\
07: 00 \\
08: 00 \\
09: 00 \\
10: 00 \\
11: 00 \\
12: 00 \\
13: 00 \\
14: 00 \\
15: 00 \\
16: 00 \\
17: 00 \\
18: 00\end{array}$ & $\begin{array}{r}- \\
31,8 \\
66,0 \\
166,5 \\
95,5 \\
117,4 \\
165,8 \\
211,4 \\
319,1 \\
143,7 \\
129,0 \\
37,6 \\
4,9\end{array}$ & $\begin{array}{r}- \\
13,6 \\
19,1 \\
69,2 \\
33,1 \\
33,2 \\
46,7 \\
58,5 \\
115,4 \\
56,1 \\
45,8 \\
14,8 \\
1,6\end{array}$ & $\begin{array}{r}- \\
66,9 \\
176,0 \\
359,3 \\
233,4 \\
314,6 \\
426,5 \\
562,8 \\
744,7 \\
320,7 \\
311,7 \\
84,5 \\
12,3\end{array}$ & $\begin{array}{r}29,2 \\
49,3 \\
131,5 \\
107,7 \\
147,8 \\
419,0 \\
425,6 \\
235,4 \\
254,1 \\
236,0 \\
48,6 \\
96,6 \\
65,7\end{array}$ & $\begin{array}{r}7,4 \\
11,8 \\
33,4 \\
34,1 \\
50,6 \\
154,2 \\
152,3 \\
93,8 \\
91,7 \\
79,6 \\
8,0 \\
17,0 \\
15,8\end{array}$ & $\begin{array}{r}82,0 \\
138,9 \\
357,6 \\
264,6 \\
344,5 \\
937,5 \\
974,2 \\
493,2 \\
575,5 \\
558,4 \\
153,0 \\
295,6 \\
187,8\end{array}$ \\
\hline MÉDIA & 124,1 & 42,3 & 301,1 & 172,8 & 57,7 & 412,5 \\
\hline
\end{tabular}

